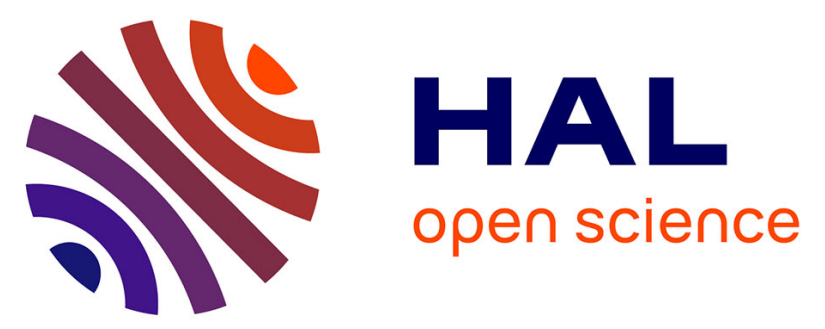

\title{
Competing phases involving spin-state and ligand structural orderings in a multistable two-dimensional spin crossover coordination polymer
}

\author{
Dao-Peng Zhang, Elzbieta Trzop, Francisco J. Valverde-Muñoz, Lucia \\ Piñeiro-López, M A Carmen Muñoz, Eric Collet, José A Real
}

\section{To cite this version:}

Dao-Peng Zhang, Elzbieta Trzop, Francisco J. Valverde-Muñoz, Lucia Piñeiro-López, M A Carmen Muñoz, et al.. Competing phases involving spin-state and ligand structural orderings in a multistable two-dimensional spin crossover coordination polymer. Crystal Growth \& Design, 2017, 17 (5), pp.27362745. 10.1021/acs.cgd.7b00218 . hal-01509702

\section{HAL Id: hal-01509702 \\ https://hal.science/hal-01509702}

Submitted on 18 Apr 2017

HAL is a multi-disciplinary open access archive for the deposit and dissemination of scientific research documents, whether they are published or not. The documents may come from teaching and research institutions in France or abroad, or from public or private research centers.
L'archive ouverte pluridisciplinaire HAL, est destinée au dépôt et à la diffusion de documents scientifiques de niveau recherche, publiés ou non, émanant des établissements d'enseignement et de recherche français ou étrangers, des laboratoires publics ou privés. 


\section{Competing phases involving spin-state and ligand structural orderings in a multistable two-dimensional spin crossover coordination polymer}

Daopeng Zhang, ${ }^{\mathrm{a}, \mathrm{b}+}$ Elzbieta Trzop,${ }^{\mathrm{c}+}$ Francisco J. Valverde-Muñoz, ${ }^{\mathrm{a}}$ Lucía Piñeiro-López, ${ }^{\mathrm{a}}$ M. Carmen Muñoz, ${ }^{\mathrm{d}}$ Eric Collet, ${ }^{* \mathrm{c}}$ and José A. Real ${ }^{* a}$

${ }^{a}$ Instituto de Ciencia Molecular (ICMol), Universidad de Valencia, C/Catedrático José Beltrán Martínez, $n^{\circ} 2,46980$ Paterna (Valencia), Spain.

${ }^{b}$ College of Chemical Engineering, Shandong University of Technology, Zibo 255049, China.

'Institut de Physique de Rennes, UMR 6251, Université de Rennes 1, 35042 Rennes cedex, France.

${ }^{d}$ Departamento de Física Aplicada, Universitat Politècnica de València, Camino de Vera s/n, E-46022, Valencia, Spain.

Magneto-structural correlations in a multi-stable $\mathrm{Fe}^{\mathrm{II}}-\mathrm{Hg}^{\mathrm{II}}$ heterometallic 2D spin crossover (SCO) coordination polymer discloses competing phases involving spin state and ligand structural ordering.

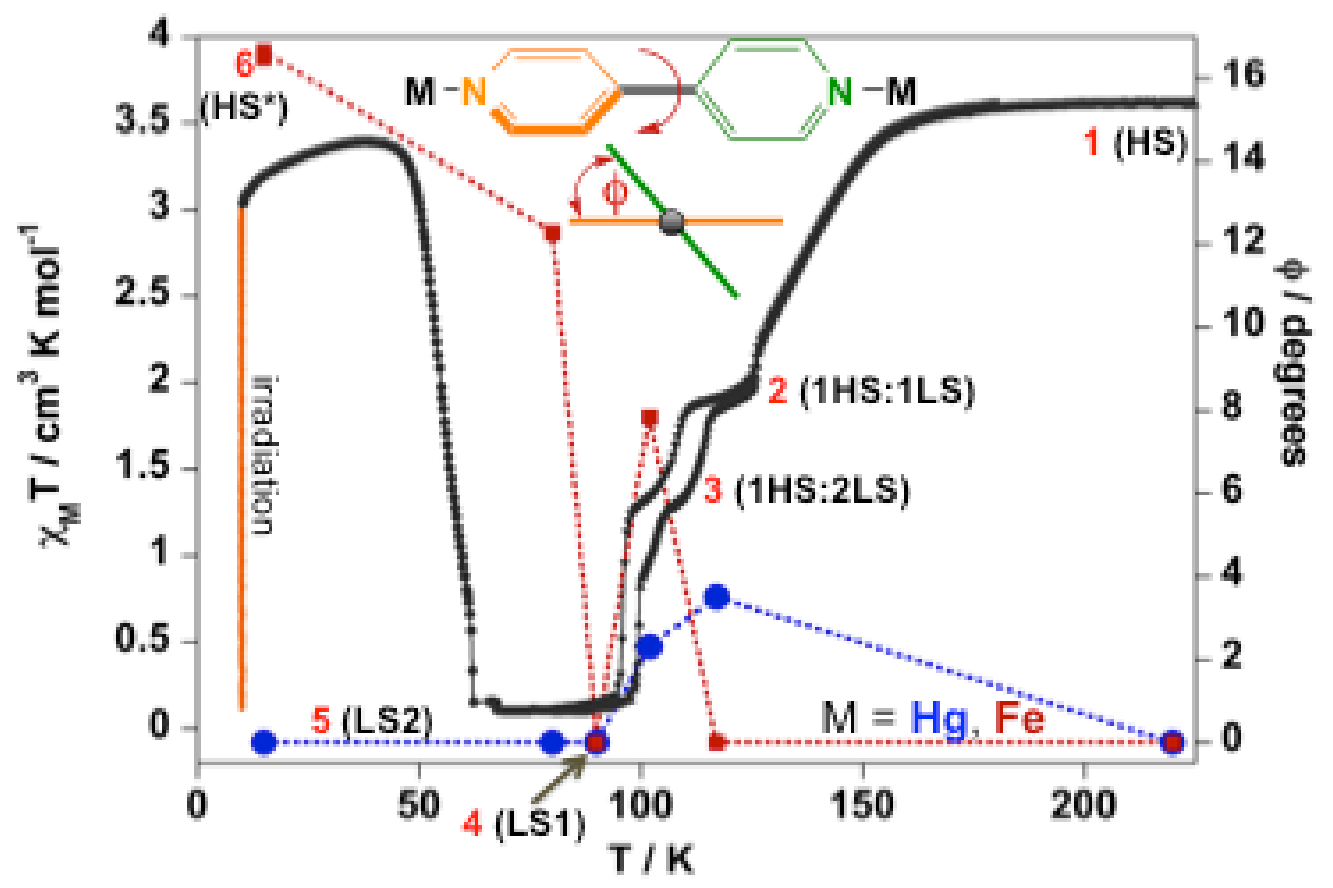




\title{
Competing phases involving spin-state and ligand structural orderings in a multistable two-dimensional spin crossover coordination polymer
}

\author{
Daopeng Zhang, ${ }^{\mathrm{a}, \mathrm{b}+}$ Elzbieta Trzop,${ }^{\mathrm{c+}}$ Francisco J. Valverde-Muñoz, ${ }^{\mathrm{a}}$ Lucía Piñeiro-López, ${ }^{\mathrm{a}}$ M. Carmen Muñoz, ${ }^{\mathrm{d}}$ Eric Collet, ${ }^{* \mathrm{c}}$ \\ and José A. Real ${ }^{* a}$
}

${ }^{a}$ Instituto de Ciencia Molecular (ICMol), Universidad de Valencia, C/Catedrático José Beltrán Martínez, $n^{\circ}$ 2, 46980 Paterna (Valencia), Spain.

${ }^{b}$ College of Chemical Engineering, Shandong University of Technology, Zibo 255049, China.

'Institut de Physique de Rennes, UMR 6251, Université de Rennes 1, 35042 Rennes cedex, France.

${ }^{d}$ Departamento de Física Aplicada, Universitat Politècnica de València, Camino de Vera s/n, E-46022, Valencia, Spain.

+ These authors contributed equally to this work.

\begin{abstract}
Competition between spin-crossover (SCO) and structural ligand ordering is identified as responsible for multi-stability and generation of six different phases in a rigid two-dimensional (2D) coordination polymer formulated $\left\{\mathrm{Fe}^{\mathrm{II}}\left[\mathrm{Hg}^{\mathrm{II}}(\mathrm{SCN})_{3}\right]\left[\mu-\left(4,4^{\prime}\right.\right.\right.$ bipy) $\left.]_{2}\right\}$ (1) $\left(4,4^{\prime}\right.$-bipy $=4,4^{\prime}$-bipyridine $)$. The structure of $\mathbf{1}$ consists of infinite linear $\left[\mathrm{Fe}\left(\mu-4,4^{\prime} \text {-bipy }\right)\right]_{\mathrm{n}^{2 n+}}$ chains linked by in-situ formed $\left\{\left[\mathrm{Hg}^{\mathrm{II}}(\mathrm{SCN})_{3}\right]_{2}\left(\mu-4,4^{\prime}-\text {-bipy }\right)\right\}^{2 \mathrm{n}-}$ anionic dimers. The thermal dependence of the high-spin fraction, $\gamma_{H S}$, features four magnetic phases defined by steps following the sequence $\gamma_{H S}=1$ (phase 1) $\leftrightarrow \gamma_{H S}=1 / 2$ (phase 2) $\leftrightarrow \gamma_{H S} \approx 1 / 3$ (phase 3) $\leftrightarrow \gamma_{H S}=0$ (phase 4). These four magnetic states are consistent with structural ordering stemming from the different commensurate or incommensurate high- and low-spin populations $[\mathrm{HS}] \leftrightarrow[\mathrm{HS}: \mathrm{LS}] \leftrightarrow \approx[\mathrm{HS}: 2 \mathrm{LS}] \leftrightarrow[\mathrm{LS} 1]$ inferred from single crystal analysis. Furthermore, two additional phases are generated at low temperature. One, LS2 $\left(\gamma_{H S}=0\right.$, phase 5), is due to spontaneous symmetry breaking of the LS1 state below $85 \mathrm{~K}$. The other, results from irradiating the low-temperature LS2 phase at $15 \mathrm{~K}$ with red light to photo-generate a HS phase of low symmetry $\left(\mathrm{HS}^{*}\right)\left(\gamma_{H S}=1\right.$, phase 6). Detailed structural studies of the six phases unravel the pivotal role played by the internal dihedral angle of the 4,4'-bipy ligands in the microscopic mechanism responsible for multistability and multi-step behavior in $\mathbf{1}$.
\end{abstract}

Competing phases involving spin-state and ligand structural orderings in a multistable two-dimensional spin crossover coordination polymer

\section{INTRODUCTION}

Iron(II) spin crossover (SCO) complexes are switchable molecular materials that respond to environmental stimuli $(\mathrm{T}$, $\mathrm{P}$, light, analytes) through changes in magnetic, optical, electrical and mechanical properties associated with the high(HS) and low-spin (LS) states of the SCO centre. The intrinsic on-off nature of the LS $\leftrightarrow$ HS switch has attracted much interest not only because it constitutes an excellent platform for investigating models of thermal-, pressure and photoinduced phase transitions ${ }^{1-13}$ in molecular materials but also because many expectancies have been created regarding to the conception of SCO-based devices, i.e. sensors, actuators and memories. ${ }^{14-24}$ This has led to an impressive growth of the SCO field in the last decade as a result of cross-seeding interaction between different areas of research ranging from coordination chemistry, materials science and solid state physics.

A pivotal current aspect that transcends the SCO research is the understanding of the elusive principles underlying cooperativity in multi-step spin transitions in the solid-state. Steps may occur when elastic forces favor competition between spatial periodicities of structural inequivalent SCO centers. For example, the presence of crystallographically distinct sites with different ligand field strengths. However, even if there is a unique SCO center in the crystal, inequivalence between SCO centers may spontaneously originate as a consequence of crystallographic symmetry breaking. Although, crystallographic symmetry breaking giving intermediate steps was previously observed for the mononuclear SCO complexes [ $\mathrm{Fe}^{\mathrm{II}}\left\{5-\mathrm{NO}_{2}\right.$-sal-N $\left.\left.(1,4,7,10)\right\}\right]$ and $\left\{\mathrm{Fe}\left[\mathrm{HC}\left(3,5-\mathrm{Me}_{2} \mathrm{pz}\right)_{3}\right]_{2}\right\}\left(\mathrm{BF}_{4}\right)_{2},{ }^{25,26}$ its relevance in the field was disclosed investigating the nature of the two-step transition [0HS:1LS] $\leftrightarrow[1 \mathrm{HS}: 1 \mathrm{LS}] \leftrightarrow[1 \mathrm{HS}: 0 \mathrm{LS}]$ in $\left[\mathrm{Fe}^{\mathrm{II}}(2-\right.$ pic) $\left.{ }_{3}\right] \mathrm{Cl}_{2} \cdot \mathrm{EtOH}^{27-29}$ So far, a relatively small number of complete two-step or incomplete (only one step of two expected) SCO events with symmetry breaking have been observed in mononuclear, ${ }^{30-39}$ polynuclear, ${ }^{40-43}$ and polymeric ${ }^{44-53} \mathrm{Fe}^{\mathrm{II}} \mathrm{SCO}$ complexes, and reviewed recently. ${ }^{54,55}$ This phenomenology has also been described for a reduced number of $\mathrm{Fe}^{\mathrm{III}},{ }^{56-60} \mathrm{Co}^{\mathrm{II}}{ }^{61}$ and $\mathrm{Mn}^{\mathrm{III}}{ }^{62}$ complexes. Most of these examples exhibit spontaneous generation of a stable state characterized by a plateau at HS molar fraction $\gamma_{\mathrm{HS}} \approx 1 / 2$ and an ordered distribution of the HS and LS centers directly observed from single crystal X-ray analysis. In some rare cases the plateau and spontaneous ordering have been observed for $\gamma_{\mathrm{HS}} \approx 2 / 3^{30,31,50}$ and $1 / 3^{36,39}$.

Concatenation of several steps/plateaus in the same crystalline SCO material is an uncommon event, which conveys the concept of multistability. It is driven by the competition between short-range and long-range elastic interaction as a result of the molecular volume change between LS and HS states, responsible for the appearance of spin-state concentration waves (SSCW). ${ }^{63-65}$ Magnetic and Mössbauer studies have demonstrated the occurrence of three steps in the multicomponent mononuclear complex $\left[\mathrm{Fe}^{\mathrm{II}}(\mathrm{dpp})_{2}\right]\left[\mathrm{Ni}(\mathrm{mnt})_{2}\right]_{2} \cdot \mathrm{MeNO}_{2}$. The steps occur in the heating mode with intermediate plateaus at $\gamma_{\mathrm{HS}} \approx 1 / 3$ and $2 / 3$ exhibiting the sequence, [0HS:1LS] $\leftrightarrow[1 \mathrm{HS}: 2 \mathrm{LS}] \leftrightarrow[2 \mathrm{HS}: 1 \mathrm{LS}] \leftrightarrow[1 \mathrm{HS}: 0 \mathrm{LS}]$.

However, structural ordering could only be evidenced for step1 where tripling of the unit, referred to the LS state, occurs in the plateau $\gamma_{\mathrm{HS}} \approx 1 / 3$ ([HS:2LS]). ${ }^{66}$ The 3D coordination polymer $\left[\mathrm{Fe}^{\mathrm{II}}(\right.$ dpsme $\left.) \mathrm{Pt}(\mathrm{CN})_{4}\right] \cdot 2 / 3 \mathrm{dpsme} \cdot \mathrm{xEtOH} \cdot \mathrm{yH}_{2} \mathrm{O}$ displays a different three-step SCO with plateaus at $\gamma_{\mathrm{HS}} \approx 1 / 3$ and $1 / 2$ consistent with the sequence, $[0 \mathrm{HS}: 1 \mathrm{LS}] \leftrightarrow[1 \mathrm{HS}: 2 \mathrm{LS}] \leftrightarrow[1 \mathrm{HS}: 1 \mathrm{LS}] \leftrightarrow[1 \mathrm{HS}: 0 \mathrm{LS}]$. 
a)

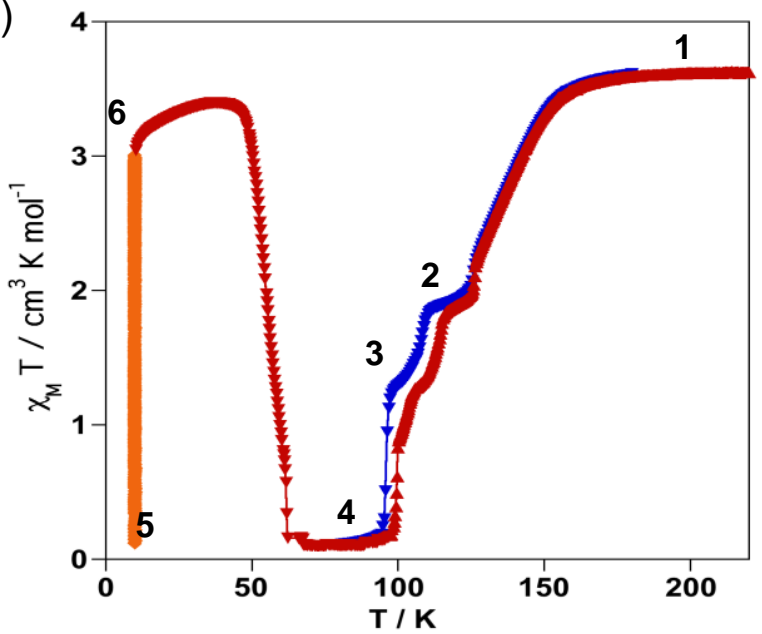

b)

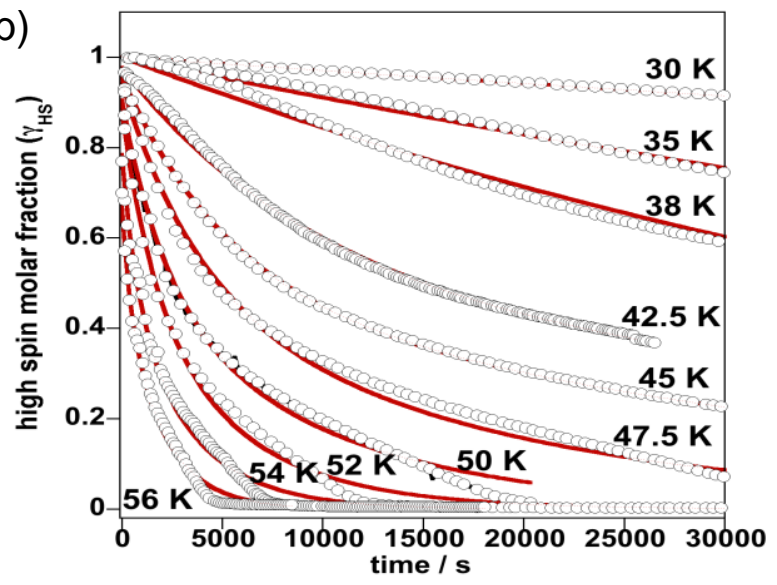

c)

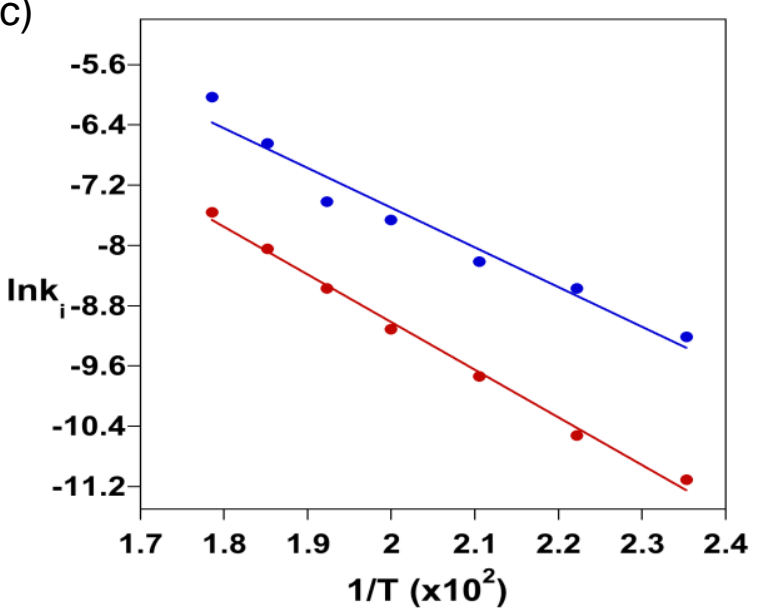

Figure 1. (a) Magnetic and photomagnetic properties of compound 1 (blue and red triangles correspond, respectively, to the cooling and heating modes. Orange line corresponds to irradiation of the sample at $10 \mathrm{~K}$, (see text). Labels 1 to 6 locate the different crystallographic phases. (b), Relaxation curves at different temperatures of the photogenerated HS* state (red lines correspond to the best fit). (c) Arrhenius plot.

In going from $\gamma_{\mathrm{HS}} \approx 1$ (0HS:1LS) to $\gamma_{\mathrm{HS}} \approx 1 / 2$ (1HS:1LS) the unit cell of the latter compound changes from monoclinic $(\mathrm{P} 2 / \mathrm{a})$ to triclinic $\left(P_{\overline{1}}\right)$ thus generating an ordered state were HS and LS layers alternate in the crystal. In a subsequent step the system attains a new ordering state at $\gamma_{\mathrm{HS}} \approx 1 / 3$ (1HS:2LS) doubling the triclinic unit cell. ${ }^{67}$ The $3 \mathrm{D}$ and $2 \mathrm{D}$ coordination polymers $\left[\mathrm{Fe}^{\mathrm{II}}(\mathrm{bipydz})\left(\mathrm{Au}^{\mathrm{I}}(\mathrm{CN})_{2}\right)_{2}\right] \cdot \mathrm{x}(\mathrm{EtOH})($ bipydz $=3,6-$ bis(4-pyridyl)-1,2-diazine) and the 2D $\left[\mathrm{Fe}_{3} \mathrm{II}^{\mathrm{I}}(\mathrm{saltrz})_{6}\left(\mathrm{M}^{\mathrm{I}}(\mathrm{CN})_{4}\right)_{3}\right] \cdot 8\left(\mathrm{H}_{2} \mathrm{O}\right)\left(\mathrm{M}^{\mathrm{II}}=\mathrm{Pd}\right.$, Pt; saltrz $=(\mathrm{E})-$ 2-(((4H-1,2,4-triazol-4-yl)imino)methyl)phenol) represent (a)
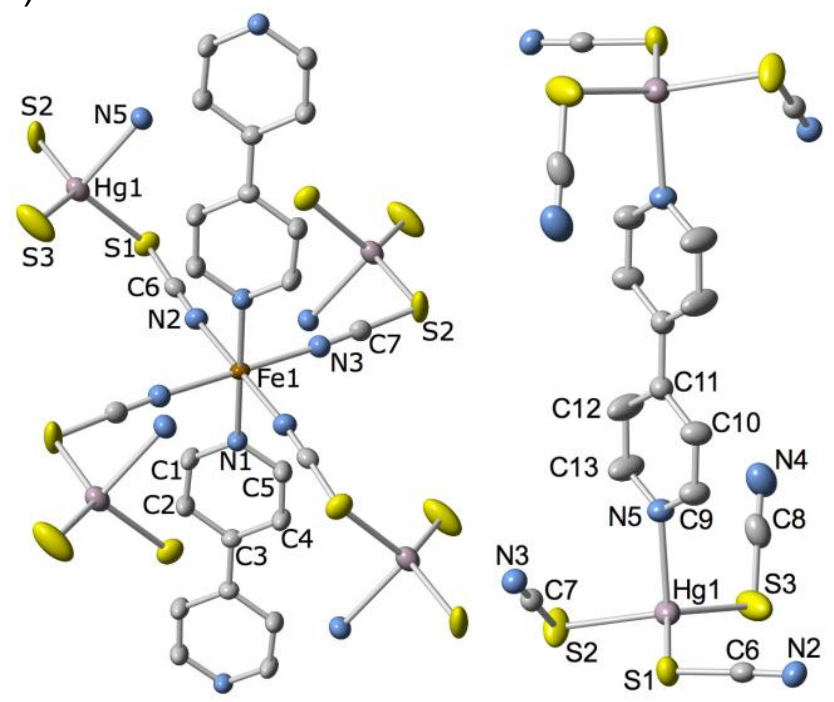

(b)
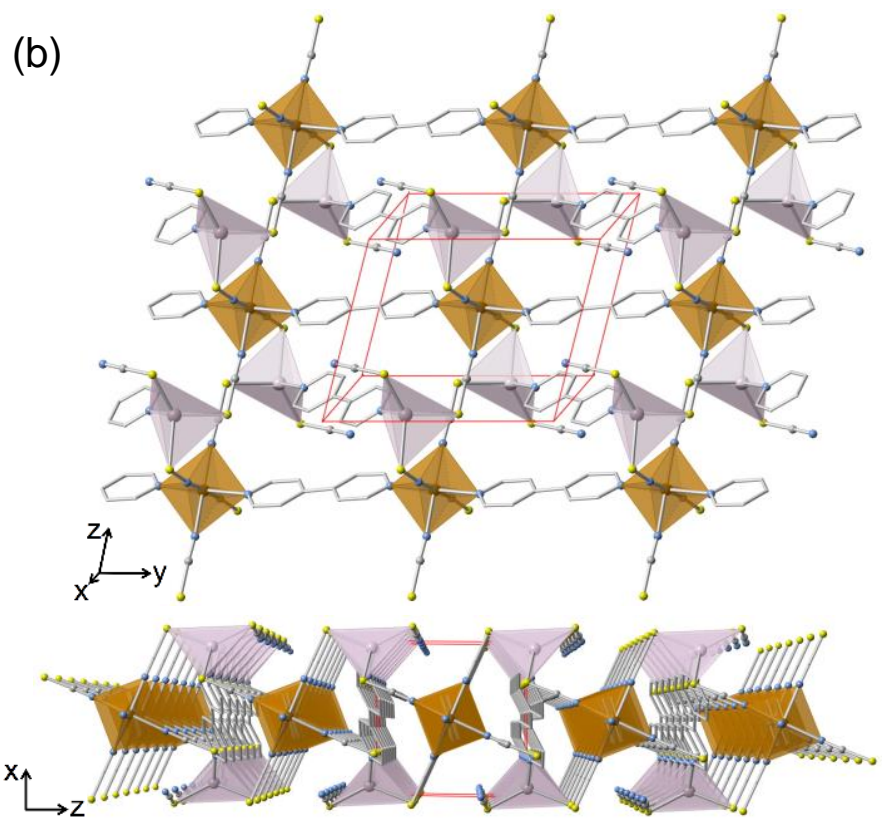

Figure 2. (a) ORTEP representation of the coordination building blocks with the atom numbering. Fragment of a layer seen along [010] (b) and [100] directions (c) (Fe: dark orange octahedrons, Hg: light-pink tetrahedrons). Thermal ellipsoids are given at $50 \%$ probability.

the first examples of four step SCO where ordering in each step has been structurally characterized. The first system displays the singular sequence of steps [0HS:1LS] $\leftrightarrow[1 \mathrm{HS}: 2 \mathrm{LS}] \leftrightarrow[1 \mathrm{HS}: 1 \mathrm{LS}] \leftrightarrow[2 \mathrm{HS}: 1 \mathrm{LS}] \leftrightarrow[1 \mathrm{HS}:$ OLS] with $\gamma_{\mathrm{HS}} \approx 0,1 / 3,1 / 2,2 / 3$ and 1 , respectively, while the sequence for the second system is different [0HS:1LS] $\leftrightarrow[1 \mathrm{HS}: 2 \mathrm{LS}] \leftrightarrow[2 \mathrm{HS}: 1 \mathrm{LS}] \leftrightarrow[5 \mathrm{HS}: 1 \mathrm{LS}] \leftrightarrow[1 \mathrm{HS}:$ OLS] which corresponds to $\gamma \mathrm{HS} \approx 0,2 / 6,4 / 6,5 / 6$ and 1 , respectively. ${ }^{68,69}$

In a recent communication we concisely introduced the two-dimensional (2D) bimetallic SCO coordination polymer formulated $\left\{\mathrm{Fe}^{\mathrm{II}}\left[\left(\mathrm{Hg}^{\mathrm{II}}(\mathrm{SCN})_{3}\right)_{2}\right]\left(4,4^{\prime} \text { bipy }\right)_{2}\right\}_{\mathrm{n}}$ (1) as a new relevant example of three-step SCO with $[0 \mathrm{HS}: 1 \mathrm{LS}] \leftrightarrow \approx[1 \mathrm{HS}: 2 \mathrm{LS}] \leftrightarrow[1 \mathrm{HS}: 1 \mathrm{LS}] \leftrightarrow[1 \mathrm{HS}: 0 \mathrm{LS}]$ 


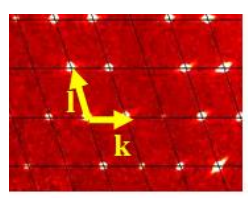

(a)

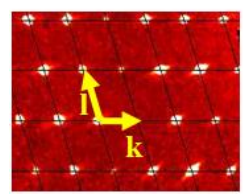

(d)

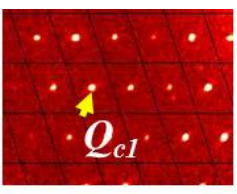

(b)

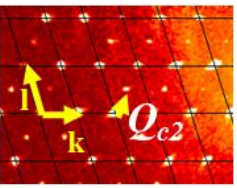

(e)

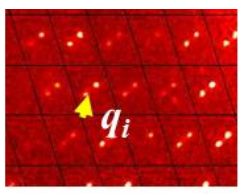

(c)

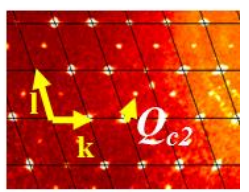

(f)
Figure 3. Reconstructed diffracted intensity of the reciprocalspace in the $0 \mathrm{kl}$ and $0.5 \mathrm{kl}$ planes for Phase 1 at $220 \mathrm{~K}$ (High Symmetry) in the 0kl plane (a); Phase 2 at $\mathbf{1 1 7 K}$ showing superstructure reflections in the $0.5 \mathrm{kl}$ plane, $Q_{c l}=$ $1 / 2 a^{*}+1 / 2 b^{*}+1 / 2 c^{*}$ (b); Phase 3 at 102K, showing satellite reflections in the $0.5 \mathrm{kl}$, plane, $q_{i}=0.48 a^{*}+0.35 b^{*}+0.42 c^{*}$ (c); Phase 4 at 90K (High Symmetry) in the 0kl plane (d); Phase 5 at $15 \mathrm{~K}$ (Low Symmetry) showing superstructure reflections in the 0kl plane, $Q_{c 2}=1 / 2 b^{*}+1 / 2 c^{*}(\mathrm{e})$; and Phase 6 at 15K (Photoinduced HS, Low Symmetry), showing superstructure reflections in the $0 \mathrm{kl}$ plane $Q_{c 2}=1 / 2 b^{*}+1 / 2 c^{*}$ (f).

sequence. ${ }^{70}$ This sequence displays successive symmetry breaking transitions and HS-LS ordering associated with each plateau, which have been rationalized in the framework of SCO devil's staircase behavior. In this context, the plateau at $\gamma_{\mathrm{HS}} \approx 1 / 2$ was described as a commensurate HS-LS SSCW characterized by a locked modulation wave-vector $Q c=$ $1 / 2 a^{*}+1 / 2 b^{*}+1 / 2 c^{*}$ generating a $\cdots$ HS-LS-HS-LS $\cdots$ order (1HS:1LS state). While, by contrast, the plateau at $\gamma_{\mathrm{HS}} \approx 1 / 3$ corresponds to an incommensurate SSCW with a modulation vector evolving around $q_{i}=0.48 \mathrm{a} *+0.35 \mathrm{~b} *+0.42 \mathrm{c} *$. Consequently, the modulation of the spatial population of HS and LS molecular states is incommensurate with the molecular lattice and the global sequence of molecular states is aperiodic.

To in depth characterize this remarkable system, here we report on its magnetic and photomagnetic properties, relaxation kinetics, as well as detailed description of the crystal structure of $\mathbf{1}$ in the states $\gamma_{\mathrm{HS}}=1$ (1HS:0LS) (phase 1), 1/2 (1HS:1LS) (phase 2), $\approx 1 / 3$ ( $\approx 1 \mathrm{HS}: 2 \mathrm{LS}$ ) (phase 3), 0 (0HS:1LS) (phases 4 and 5) and the photoinduced HS state(HS*) (phase 6). We have found that, in addition to the aforementioned commensurable and incommensurable spinstate ordering symmetry breaking on the plateaus, other types of symmetry breaking due to ligand ordering occurs at low temperature. The LS state displays a pure crystallographic transition around $85 \mathrm{~K}$. The high-symmetry LS1 phase 4 at $90 \mathrm{~K}$ is isostructural to the HS phase at $220 \mathrm{~K}$, while below $85 \mathrm{~K}$ the structure losses symmetry with doubling of the unit cell due to ligand ordering (LS2) (phase 5). Interestingly, the photogenerated $\mathrm{HS}^{*}$ state at $15 \mathrm{~K}$ preserves this unit cell doubling thus generating a photo-induced metastable of lower symmetry than the HS state reached at high temperature at thermal equilibrium.

\section{RESULTS AND DISCUSSION}

Magnetic and photomagnetic data.

The thermal dependence of $\chi_{M} T$ product $\left(\chi_{M}=\right.$ magnetic susceptibility, $\mathrm{T}$ temperature) of $\mathbf{1}$ is shown in Figure 1a. In the interval $300-190 \mathrm{~K}, \chi_{M} T \approx 3.67 \mathrm{~cm}^{3} \mathrm{~K} \mathrm{~mol}^{-1}$ is practically
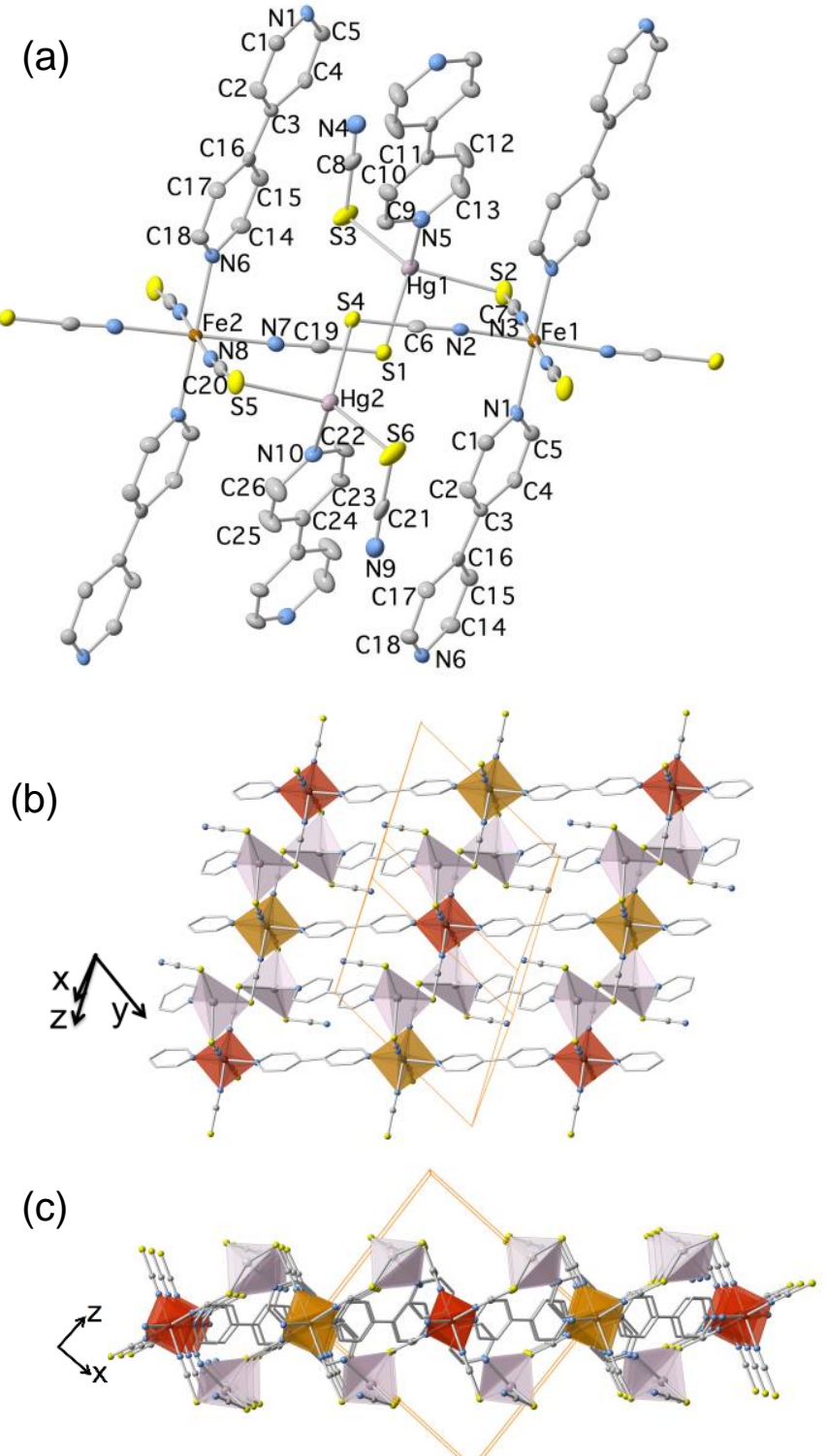

Figure 4. (a) View of a representative molecular fragment (ORTEP representation) showing the two crystallographically distinct $\mathrm{Fe}^{\mathrm{II}}$ atoms $\mathrm{Fe}$ (LS) and $\mathrm{Fe}$ 2(HS) and relevant atom numbering; (b) and (c) Perspective views of a layer of 1 at $120 \mathrm{~K}\left(\mathrm{Fe}^{\mathrm{II}} \mathrm{LS}\right.$ and $\mathrm{HS}$ are represented as red (Fe1) and dark orange octahedrons (Fe2)). Thermal ellipsoids are given at $50 \%$ probability.

constant and consistent with a $\mathrm{Fe}^{\mathrm{II}} \mathrm{HS}(\mathrm{S}=2)$ (phase 1$)$. Below $170 \mathrm{~K}, \chi_{M} T$ drops rapidly in a first step, reaching a first plateau in the temperature interval $125-108 \mathrm{~K}$. On the plateau ca. $50 \%$ of HS $\rightarrow$ LS conversion $\left(\chi_{M} T \approx 1.90 \mathrm{~cm}^{3} \mathrm{~K} \mathrm{~mol}^{-1}\right.$ at $119 \mathrm{~K}$ ) takes place (phase 2). On cooling further, a second drop occurs and another plateau is reached in the interval 108$96 \mathrm{~K}$, which corresponds almost to ca. $66 \%$ of conversion $\left(\chi_{M} T \approx 1.33 \mathrm{~cm}^{3} \mathrm{~K} \mathrm{~mol}^{-1}\right.$ ) (phase 3). Finally, a third sharp drop around $96 \mathrm{~K}$ and attains a value of $\chi_{M} T \approx 0.1 \mathrm{~cm}^{3} \mathrm{~K} \mathrm{~mol}^{-}$ ${ }^{1}$ at $93 \mathrm{~K}$ where the conversion towards the LS state is almost complete (phase 4). The heating mode reproduces the three steps but the two low-temperature transitions occur at $\mathrm{T}_{\mathrm{c}}$ 's ca. 4-6 K higher than in the cooling mode (two cycles performed at scan temperature rates of 0.5 and $1 \mathrm{~K} \mathrm{~min}^{-1}$ ). This threestep transition corresponds rather well to the sequence [0HS:1LS] $\leftrightarrow \approx[1 \mathrm{HS}: 2 \mathrm{LS}] \leftrightarrow[1 \mathrm{HS}: 1 \mathrm{LS}] \leftrightarrow[1 \mathrm{HS}: 0 \mathrm{LS}]$. It is worth stressing that this magnetic behavior is perfectly reproducible after a great number of cycles and that the samples (single crystals) are very stable. 


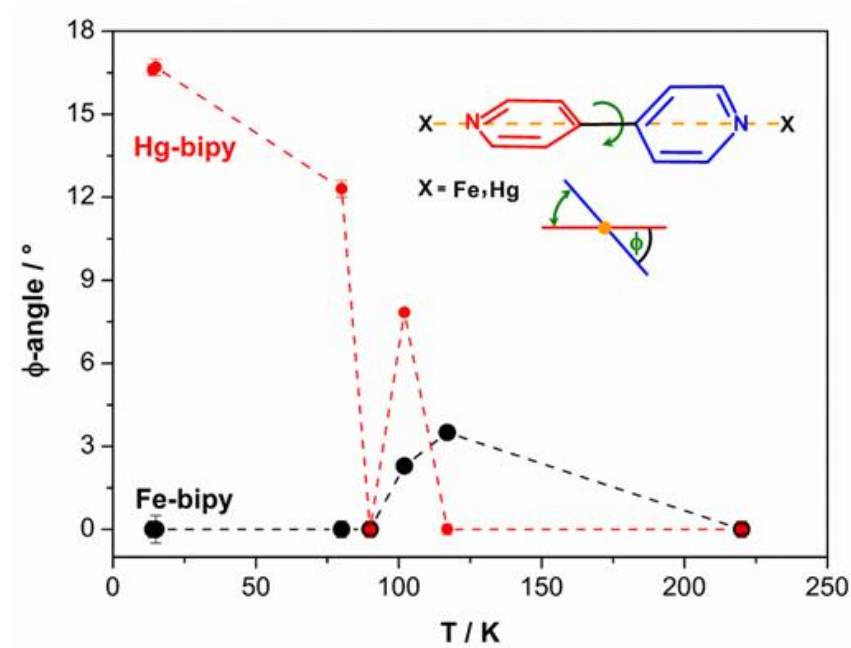

Figure 5. Change of the angle between the py rings of the 4,4'bipy ligands during spin transition with temperature and under light excitation.

Photogeneration of the metastable HS* state at low temperature, the so-called light induced excited spin state trapping experiment $(\text { LIESST) })^{71}$ was carried out on a microcrystalline sample $(2.76 \mathrm{mg})$ of $\mathbf{1}$ (Figure 1a). The sample was cooled down to $10 \mathrm{~K}$ where $\chi_{M} T \approx 0.09 \mathrm{~cm}^{3} \mathrm{~K}$ $\mathrm{mol}^{-1}$. Then the sample was irradiated with red light $(\lambda=633$ $\mathrm{nm})$ rapidly attaining (less than 30') a saturation $\chi_{M} T$ value ca. $3.0 \mathrm{~cm}^{3} \mathrm{~K} \mathrm{~mol}^{-1}$. Light irradiation was then switched off and the temperature increased at a rate of $0.3 \mathrm{~K} \mathrm{~min}^{-1}$. In the $10-38 \mathrm{~K}$ temperature range $\chi_{M} T$ increased up to a maximum value ca. $3.40 \mathrm{~cm}^{3} \mathrm{~K} \mathrm{~mol}^{-1}$ at $38 \mathrm{~K}$, which reflects thermal population of the different microstates arising from the zerofield splitting of the HS* $(\mathrm{S}=2)$ state, and suggests that the light-induced population of the HS* state is virtually complete at $10 \mathrm{~K}$ (phase 6). At temperatures greater than 39 $\mathrm{K}, \chi_{M} T$ drops rapidly and reaches a value about $0.09 \mathrm{~cm}^{3} \mathrm{~K}$ $\mathrm{mol}^{-1}$ at ca. $62 \mathrm{~K}$ indicating complete HS $*$ LS relaxation. The $\mathrm{T}_{\text {LIESST }}$ temperature ${ }^{72}$ determined from the maximum variation of $\chi_{M} T$ in the HS $\rightarrow$ LS relaxation is equal to $54 \mathrm{~K}$.

The HS* $\rightarrow$ LS relaxation kinetics has been investigated in the temperature interval $30-56 \mathrm{~K}$ (Figure $1 \mathrm{~b}$ ). In the region $56-42.5 \mathrm{~K}$ the curves were reasonably well-simulated using two equally weighed exponential functions. Because of the relaxation is significantly reduced, only a simple exponential was used at lower temperatures. From derived $\mathrm{k}_{1}$ and $\mathrm{k}_{2}$ values, gathered in Table $\mathrm{S} 1$, and the corresponding Arrhenius plot in the interval 56-42.5 K (Figure 1c) the preexponential factors $\mathrm{k}_{\mathrm{i}}(\mathrm{T} \rightarrow \infty)=21$ (1) and 38 (2) $\mathrm{s}^{-1}$ and the activation energies $\mathrm{E}_{\mathrm{i}}^{\mathrm{a}}=527(1)$ and $440(2) \mathrm{cm}^{-1}$ have been estimated. These values are consistent with other related SCO compounds. $^{73}$ Usually, these parameters are largely underestimated due to coexistence of tunneling and thermal activation in the $30-50 \mathrm{~K}$ temperature range. Observation of a bi-exponential kinetic regime could be consistent with the formation of an ordered intermediate HS*-LS phase and its subsequent relaxation to the LS state. However, although the $\chi_{M} T$ vs $T$ plot shows a slight change of slope, there is no a clear plateau at ca. $50 \%$ of relaxation (even irradiating for 12 h). In this respect, a recent theoretical study underlined that the step may hardly appear during the relaxation process because the long-range HS-LS order difficultly forms. ${ }^{63}$

\section{Variable temperature single crystal analysis}

Single crystal diffraction data have been recorded in the different phases at $220 \mathrm{~K}, 117 \mathrm{~K}, 102 \mathrm{~K}, 90 \mathrm{~K}, 80 \mathrm{~K}, 15 \mathrm{~K}$

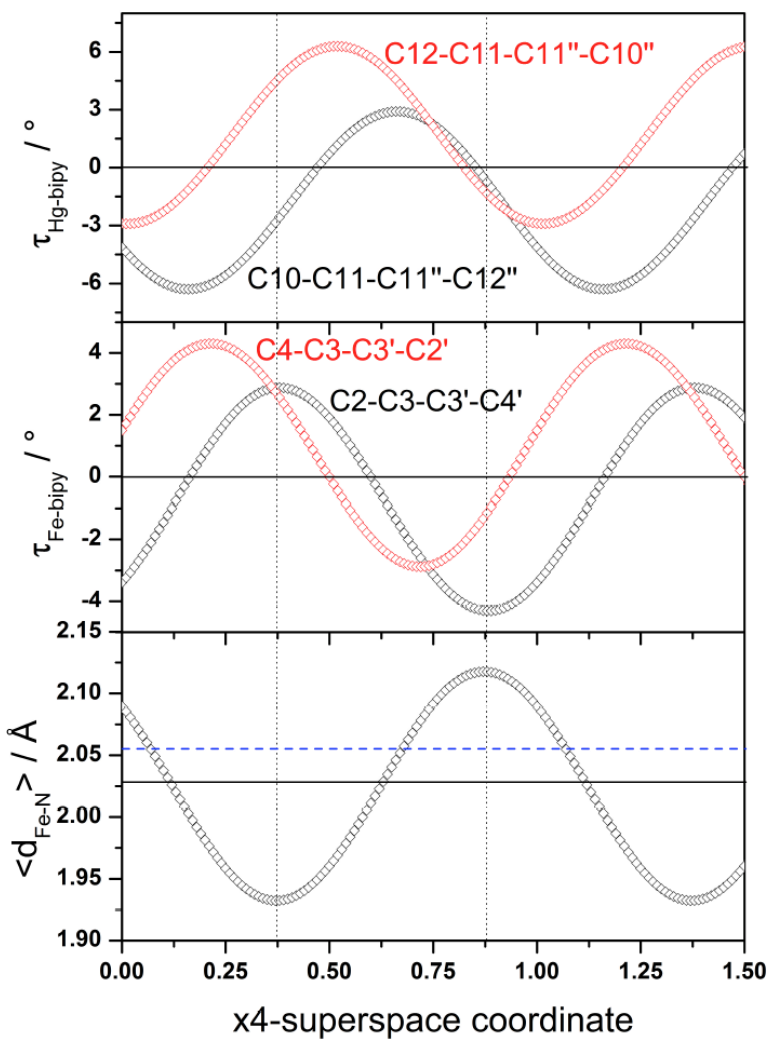

Figure 6. Modulation along the superspace coordinate $\mathrm{x}_{4}$ of the torsion angles between 4,4'-bipy ligands around the $\mathrm{Hg}$, around the $\mathrm{Fe}$ and of the $\mathrm{Fe}-\mathrm{N}$ bond. The almost sinusoidal modulation of $\mathrm{Fe}-\mathrm{N}$ around ca. $2.027 \AA$ (thick line) corresponds to $\gamma_{H S} \approx 0.34$ observed by magnetism (symmetry codes ' and " are 1-x,-y,1-z and 1-x,-y,2-z respectively).

and at $15 \mathrm{~K}$ after irradiation with a red laser $(\lambda=660 \mathrm{~nm})$. Table 1, Table S2, and Table S3 gather relevant crystal data and selected bond distances and angles, respectively. The unit cell of 1 is triclinic $P_{\overline{1}}$ whatever temperature. From a crystallographic point of view the thermal dependence of the unit cell volume, $\mathrm{V}$, reproduces reasonably well the $\chi_{M} T$ vs. $T$ plot (Figure S1) during cooling and heating. While heating the sample from phase 5 to phase 1, we observe the same structural reorganizations on the steps. The phase transition from phase $\mathbf{5}$ to $\mathbf{4}$ is continuous, so the symmetry change occurs at $85 \mathrm{~K}$ in both cases. The phase transition from phase 4 to 3 occur at almost the same temperature in the heating and cooling modes, as observed by volume change and appearance of satellite peaks. In the same way, the phase transition from phase 3 to 2 occurs around $108 \mathrm{~K}$ in both cases. The difference in thermal behavior between X-ray and magnetism between phase $\mathbf{4}$ and $\mathbf{2}$ is due to kinetics effects as magnetic curves were recorded with $3 \mathrm{~K} / \mathrm{min}$ ramp, whereas X-ray data were collected with a ramp of $\sim 0.1$ $\mathrm{K} / \mathrm{min}$. The crystals display marked thermochromism associated with the SCO. They reversibly change from lightorange at room temperature (HS state) to deep-red (LS state) at liquid nitrogen temperature. This drastic change of color, is due to the presence of relatively intense ${ }^{1} \mathrm{~A}_{1} \rightarrow{ }^{1} \mathrm{~T}_{1}$ and ${ }^{1} \mathrm{~A}_{1} \rightarrow{ }^{1} \mathrm{~T}_{2}$ absorptions characteristic of the LS state and the lack of strong charge-transfer bands (Figure S2).

Phase 1, $\gamma_{\mathrm{HS}}=1$, HS structure, high symmetry. At 220 $\mathrm{K}$, there is a single $\mathrm{Fe}^{\mathrm{II}}$ site lying on an inversion center. The asymmetric unit consists of one axially coordinated $\mathrm{N}$ atom belonging to a 4,4 '-bipy ligand $(\mathrm{Fe}-\mathrm{N} 1=2.183(3) \AA)$ and two 
equatorial $\mathrm{N}$ atoms belonging to two crystallographically distinct NCS groups $(\mathrm{Fe}-\mathrm{N} 2=2.153(3)$ and $\mathrm{Fe}-\mathrm{N} 3=$ 2.137(3)) (Figure 2). The average Fe1-N bond length of the slightly distorted $\left[\mathrm{Fe}^{\mathrm{II}} \mathrm{N}_{6}\right]$ octahedron, $\langle\mathrm{Fe} 1-\mathrm{N}\rangle=2.158(3) \AA$, is consistent with the $\mathrm{Fe}^{\mathrm{II}}$ atom in the HS state, in agreement with the $\chi_{M} T$ value at same temperature. The small distortion of the $\left[\mathrm{Fe}^{\mathrm{II}} \mathrm{N}_{6}\right]$ octahedron is also reflected on the sum of deviations, from the ideal octahedron, of the 12 "cis" $\mathrm{N}-\mathrm{Fe}-\mathrm{N}$ angles, $\left.\Sigma^{\text {oct }}=\sum_{i=1}^{12}\left|\theta_{i}-90^{\circ}\right|\right)=11.24^{\circ} .{ }^{74-78}$

Two consecutive $\mathrm{Fe}^{\mathrm{II}}$ centers are bridged by a strictly planar 4,4'-bipy ligand lying on an inversion center, thereby defining $\left[\mathrm{Fe}\left(\mu-4,4^{\prime} \text { 'bipy }\right)\right]_{\mathrm{n}}{ }^{2 \mathrm{n}+}$ chains running along [010] direction. These chains are slightly undulated since two consecutive $\mathrm{Fe}^{\mathrm{II}}$ are alternatively situated ca. $0.42 \AA$ above and below the plane defined by the 4,4 '-bipy. One of the thiocyanate ligands is essentially linear, N3-C7-S2 = 179.1(3) ${ }^{\circ}$ while the other, N2-C6-S1, separates $3.7^{\circ}$ (average) from linearity due to positional disorder shown by the $\mathrm{S} 1$ atom. The $\mathrm{Fe}-\mathrm{N}(-\mathrm{C}-\mathrm{S})$ bonds are almost collinear showing a slight off-axis tilt of $4.1^{\circ}$ for $\mathrm{Fe}-\mathrm{N} 3-\mathrm{C} 7-\mathrm{S} 2$ and $5.8^{\circ}$ (average) for Fe-N2-C6-S1.

The charge of the $\left[\mathrm{Fe}\left(\mu-4,4^{\prime}-\text { bipy }\right)\right]_{n}{ }^{2 n+}$ chains is balanced by in situ generated centrosymmetric $\left\{\left[\mathrm{Hg}^{\mathrm{II}}(\mathrm{SCN})_{3}\right]_{2}(\mu-4,4\right.$ 'bipy) $\}^{2-}$ dimeric moieties constituted of two strongly distorted tetrahedral $\left[\mathrm{Hg}^{\mathrm{II}} \mathrm{S}_{3} \mathrm{~N}\right]$ coordination sites. The sum of deviations, from the ideal tetrahedron, of the 6 "cis" angles around the $\mathrm{Hg}$ ion, $\left.\Sigma^{\text {tet }}=\sum_{i=1}^{6}\left|\theta_{i}-109.5^{\circ}\right|\right)=79.2^{\circ}$ confirms the strong distortion from the regular geometry (Figure 2a). ${ }^{79}$ The tetrahedrons are linked through a second crystallographically independent 4,4'-bipy ligand (Hg-N5 = 2.407(3) А), which is also strictly planar. The $\mathrm{Hg}-\mathrm{S}(-\mathrm{C}-\mathrm{N})$ bonds are strongly tilted [Hg-S3-C8-N4, 98.5 ; Hg-S2-C7N3, 93.7; $\mathrm{Hg}-\mathrm{S} 1-\mathrm{C} 6-\mathrm{N} 2, \quad 104.1^{\circ}$ (average)]. One thiocyanate, N4-C8-S3 (Hg-S3 = 2.4253(11) $\AA$ ), acts as a terminal ligand while the other two, N3-C7-S2 (Hg-S2 =

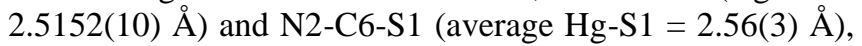
act as bis-monodentate bridging ligands coordinating the equatorial positions of the $\mathrm{Fe}$ sites of consecutive $[\mathrm{Fe}(\mu-4,4$ 'bipy) $]_{\mathrm{n}}{ }^{2 \mathrm{n}}$ chains, thus defining infinite layers which stack along [100] direction (Figure 2b). Between two consecutive layers there are very few relevant contacts, i.e. $\mathrm{C} 8 \cdots \mathrm{C} 12$ ' $=$ 3.611(5), C8 $\cdots \mathrm{C}^{\prime}{ }^{\prime}=3.513(5) \AA, \mathrm{C} 6 \cdots \mathrm{S} 2=3.457(6)$.

Phase 2, $\gamma_{H S} \approx 1 / 2$, Commensurate SSCW. In the 108-125 $\mathrm{K}$ plateau, the unit cell doubles along $(\boldsymbol{a}+\boldsymbol{b}+\boldsymbol{c})$ displaying characteristic superstructure Bragg peaks at $Q_{c l}=1 / 2 \boldsymbol{a}^{*}+1 / 2 \boldsymbol{b}^{*}+1 / 2 \boldsymbol{c}^{*}$ (Figure 3). A fragment of the structure in this doubled cell with new lattice parameters together with the atom numbering of the asymmetric unit is displayed in Figure 4a. The structural refinement of the double cell at 117 $\mathrm{K}$ reveals the occurrence of two distinct centrosymmetric $\mathrm{Fe}^{\mathrm{II}}$ sites: site 1 with $\langle\mathrm{Fe} 1-\mathrm{N}\rangle \approx 1.968(3) \AA$ and $\left(\sum^{\mathrm{oct}}\right)_{1}=5.5^{\circ}$ is mainly LS while site 2 with $\langle\mathrm{Fe} 2-\mathrm{N}\rangle \approx 2.146(3) \AA$ and $\left(\Sigma^{\mathrm{oct}}\right)_{2}$ $=15.5^{\circ}$ is mainly HS. As a consequence, the 4,4'-bipy ligands lose the planarity and consequently the inversion center in the slightly undulating $[\mathrm{Fe}(\mu-4,4 \text { '-bipy })]_{\mathrm{n}}{ }^{2 \mathrm{n}+}$ chains. The twist angle, $\phi$, formed in between planes defined separately on two pyridyl rings of $4,4^{\prime}$-bipy ligand is $3.5^{\circ}$ on the Fe-center and its related to the loss of inversion center on the ligand (see Figure 5). Besides, there are two crystallographically distinct centrosymmetric $\left\{\left[\mathrm{Hg}^{\mathrm{II}}(\mathrm{SCN})_{3}\right]_{2}(\mu-4,4 \text { '-bipy })\right\}^{2-}$ units which show little differences with respect to the $220 \mathrm{~K}$ structure. Their 4,4'-bipy ligands keep the inversion centers and remain planar, $\phi^{\prime}=0$ (Figure 5), and the coordination spheres of $\mathrm{Hg} 1$ and $\mathrm{Hg} 2$ are strongly distorted with $\left(\Sigma^{\text {tet }}\right)_{\mathrm{i}}$ values of $87.35^{\circ}$ and $75.05^{\circ}$, respectively. The $2 \mathrm{D}$ network accommodates the changes associated with the SCO at Fel through small readjustments, which mainly involve angular changes in the $\left[\mathrm{HgNS}_{3}\right]$ and $\left[\mathrm{Fe} 2 \mathrm{~N}_{6}\right]$ cores, i.e. $\left(\Sigma^{\mathrm{tet}, \mathrm{oct}}\right)_{\mathrm{i}}$ changes by $+8.5^{\circ}$ and $-4.1^{\circ}$ for $\mathrm{Hg} 1$ and $\mathrm{Hg} 2$-centers, and by $+4.2^{\circ}$ for $\mathrm{Fe} 2$-center in comparison to the geometry of phase 1 . The Fe-NCS tilt angles found in the range $3.8-5^{\circ}$ remain practically unaltered.

Within the 2D network, the sites Fe1(LS) and Fe2(HS) alternate affording an ordered chessboard like state (Figure $4 b)$. The crystal packing consists of a pile of networks along [101] and defines slices of HS and LS layers alternating along [001] (Figure 4c). With respect to the crystalline lattice of the HS phase, this situation can be described as the formation of a spin-state concentration plane wave along the wave vector $Q_{c l}=1 / 2 a^{*}+1 / 2 b^{*}+1 / 2 c^{*}$, which is commensurate with the initial $\left(a^{*}, b^{*}, c^{*}\right)$ reciprocal lattice. The crystal structure consists then of mainly HS and LS stripes alternating in a ...HS-LSHS-LS... sequence along $Q_{c 1}$.

Phase 3, $\gamma_{\mathrm{HS}} \approx \mathbf{1 / 3}$, incommensurate SSCW. Upon cooling, a new symmetry change takes place on the $96-108 \mathrm{~K}$ step. The Bragg peaks at $Q_{c l}$ characteristic of the formation of the commensurate SSCW disappear, whereas new peaks appear at $Q=\mathrm{h} \boldsymbol{a}^{*}+\mathrm{k} \boldsymbol{b}^{*}+\mathrm{l} \boldsymbol{c}^{*}+\mathrm{m} \boldsymbol{q}_{i}$ with $q_{i}=\alpha \boldsymbol{a}^{*}+\beta \boldsymbol{b}^{*}+\gamma \boldsymbol{c} *$ (Figure 3). Since $\alpha \approx 0.48(1), \beta \approx 0.35(1)$ and $\gamma \approx 0.42(1)$ cannot be expressed as simple fractions the crystalline structure is no more $3 \mathrm{D}$ periodic, but incommensurately modulated with respect to the HS $(\boldsymbol{a}, \boldsymbol{b}, \boldsymbol{c})$ lattice. It belongs to the 4D superspace group $P_{\overline{1}}(\alpha, \beta, \gamma) 0$ (SSG number 2.1.1.1). ${ }^{70}$ The structural analysis shows that the average $3 \mathrm{D}$ periodic cell is similar to the HS lattice. The structure is characterized by a unique Fe1 site with $\langle\mathrm{Fe} 1-\mathrm{N}\rangle=2.025(9) \AA$ and $\Sigma_{1}=$ $9.3^{\circ}$. The corresponding average bond length change $\Delta(<\mathrm{Fe}-$ $\mathrm{N}>)=(2.058-2.024)=0.034 \AA$ represents ca. $17-16 \%$ of additional $\mathrm{HS} \rightarrow \mathrm{LS}$ transformation, which agrees well with the estimated change observed from $\chi_{M} T$ (ca. 16\%). The overall transformation is consistent with $\gamma_{H S} \approx 1 / 3$ found in magnetic measurements. Unlike other previous examples with $\gamma_{H S} \approx 1 / 3$, this state does not correspond to a unit cell tripling with ordering, e.g. LS-LS-HS, as the new Bragg peaks are at incommensurate positions. The crystal structure refinement in the $4 \mathrm{D}$ superspace group $P_{\overline{1}}(\alpha, \beta, \gamma) 0$ explains the ordering on this step. In the full structure model of a modulated structure, the atoms must be described by their positions in the average $(\boldsymbol{a}, \boldsymbol{b}, \boldsymbol{c}) 3 \mathrm{D}$ unit cell and by their modulation functions along the fourth dimension coordinate $\mathrm{x}_{4}$ of the superspace.

The modulation of the $\langle\mathrm{Fe}-\mathrm{N}\rangle$ bond length along $\mathrm{x}_{4}$, as seen in Figure 6 (bottom), characterizes the presence of stripes of HS and LS molecular states, perpendicular to the direction of the incommensurate modulation vector $\boldsymbol{q}_{i}$, i.e. of a SSCW incommensurate with the $(\boldsymbol{a}, \boldsymbol{b}, \boldsymbol{c})$ lattice. Here, the torsion angles, $\tau$ and $\tau^{\prime}$, defined respectively by the $4,4^{\prime}$ '-bipy ligands of the $\left\{\left[\mathrm{Hg}^{\mathrm{II}}(\mathrm{SCN})_{3}\right]_{2}\left(\mu-4,4^{\prime} \text {-bipy }\right)\right\}^{2-}$ and $[\mathrm{Fe}(\mu-4,4$ 'bipy) $]_{\mathrm{n}}{ }^{2 \mathrm{n}+}$ moieties are also modulated along $\mathrm{x}_{4}$, underlying that the spin-state ordering is accompanied by a ligand ordering Figure 6 (top and middle). In this incommensurate phase due to the modulations, both $\phi$ and $\phi^{\prime}$ angles are given in their average representation. They are no planar (Figure 5) due to the loss of the inversion centers on the 4,4'-bipy ligands for $\mathrm{Fe}$ - and $\mathrm{Hg}$-moieties.

Phase 4, $\gamma_{\mathrm{HS}} \approx 0, \mathrm{LS1}$ structure. The crystal structure in the LS state has been investigated at $90 \mathrm{~K}, 80 \mathrm{~K}$ and $15 \mathrm{~K}$. At $90 \mathrm{~K}$ the crystal remains triclinic with a $(a, b, c)$ cell similar to 


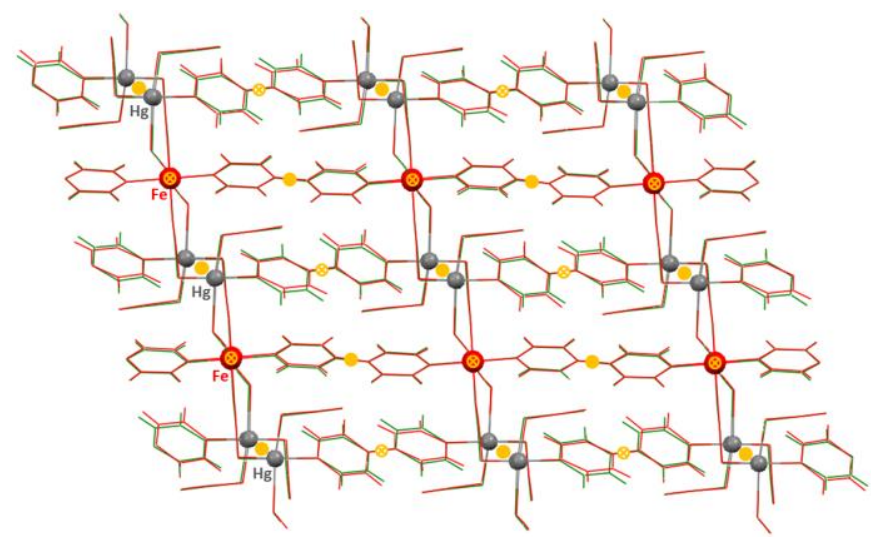

Figure 7. Overlay of high-symmetry LS state at $90 \mathrm{~K}$ (green) with low-symmetry LS state at $15 \mathrm{~K}$ (red). Filled and crossed circles red circles represent, respectively, the remaining and lost inversion centres when the crystal moves from $90 \mathrm{~K}$ to 80 or $15 \mathrm{~K}$

the one of the HS phase: the total volume contraction of the unit cell $\Delta \mathrm{V}_{\mathrm{c}}$ in the $220-90 \mathrm{~K}$ interval is $41.45 \AA^{3}$ (Figure $\mathrm{S} 1)$. This value corresponds to the sum of the volume change due to thermal expansion $\left(\Delta \mathrm{V}(\mathrm{T}) \approx \mathrm{V}_{\mathrm{HS}} \cdot \alpha_{\mathrm{V}} \cdot \mathrm{T}\right)$ and $\mathrm{SCO}$ $\left(\Delta \mathrm{V}_{\mathrm{SCO}}\right)$. From the thermal dependence of the unit cell volume in the temperature range $172-250 \mathrm{~K}$, where $\gamma_{\mathrm{HS}}$ is constant and $\approx 1$, the volumetric thermal expansion coefficient, $\alpha_{\mathrm{v}}=(1 / \mathrm{V})(\partial \mathrm{V} / \partial \mathrm{T})$, is estimated to be in the interval 1.4-1.8 $\times 10^{-4} \mathrm{~K}^{-1}$ and then $\Delta \mathrm{V}_{\mathrm{SCO}}$ is about $28.2 \AA^{3}$ (see thermal variation of the cell volume and lattice parameters $a$, $b$, and $c$ both in cooling and heating modes respectively in Figure S1 and S3). These values correspond well with what it is expected for a complete HS-LS transformation for one $\mathrm{Fe}^{\mathrm{II}}$ center (LS1 state). ${ }^{80}$ The structure consists of a single Fe site, and its average Fe-N bond length $\langle\mathrm{Fe} 1-\mathrm{N}\rangle=1.961$ (3) $\AA$ and the angular distortion $\left(\Sigma^{\text {oct }}\right)_{1}=7.6^{\circ}$, as well as the overall $\Delta \mathrm{d}(\mathrm{Fe}-\mathrm{N})=0.197(3) \AA$ bond length change upon SCO are fully consistent with a LS state. Apart from these changes, the $90 \mathrm{~K}$ structure does not present other relevant differences with respect to the structure at $220 \mathrm{~K}$ (Figure S4). For example, i) at both temperatures the assymmetric unit is the same; ii) both crystallographically distinct 4,4'-bipy bridging ligands become again planar, $\phi=\phi^{\prime}=0$; iii) the deviation from $180^{\circ}$ of the $\mathrm{NCS}^{-}$groups decreases a little being the largest separation $2.7^{\circ}$ for $\mathrm{S} 1-\mathrm{C} 6-\mathrm{N} 2$; iv) the tilt angle of the Fe-NCS moiety is smaller by ca. $2^{\circ}$; and v) $\Sigma^{\text {tet }}$ for $\mathrm{Hg}$ is virtually the same $\left(75.7^{\circ}\right)$. Similarly, the interaction between two consecutive layers is only modified a little: $\mathrm{C} 8 \cdots \mathrm{C} 8^{\mathrm{i}}=$ $3.432(6) \AA, \mathrm{C} 8 \cdots \mathrm{C} 13^{\mathrm{i}}=3.661(6) \AA, \mathrm{C} 8 \cdots \mathrm{C} 12^{\mathrm{i}}=3.571(6) \AA$ and $\mathrm{C} 6 \cdots \mathrm{S} 2^{\mathrm{i}}=3.485(6) \AA$.

Phase 5, $\gamma \mathrm{HS} \approx 0$, low symmetry LS2 structure. The 80 $\mathrm{K}$ and $15 \mathrm{~K} \mathrm{LS}$ structures are essentially identical and denote the occurrence of a pure crystallographic symmetry breaking phase transition, associated with a different type of unit-cell doubling, characterized by the appearance of Bragg peaks at $\boldsymbol{Q}_{\boldsymbol{c} 2}=1 / 2 \boldsymbol{b}^{*}+1 / 2 \boldsymbol{c}^{*}$ below $85 \mathrm{~K}$ (Figure 3e). A representation of the asymmetric unit at $80-15 \mathrm{~K}$ is given in Figure S5. In the double unit cell the $\left[\mathrm{Fe}\left(\mu-4,4^{\prime}-\text {-bipy }\right)\right]_{n}{ }^{2 n+}$ chains are defined by non centrosymmetric $\mathrm{Fe}^{\mathrm{II}}$ sites linked by planar centrosymmetric 4,4'-bipy bridges, $\phi=0$, while the $\left\{\left[\mathrm{Hg}^{\mathrm{II}}(\mathrm{SCN})_{3}\right]_{2}\left(\mu-4,4^{\prime} \text { 'bipy }\right)\right\}^{2-}$ units are constituted of two crystallographically distinct $\operatorname{Hg}^{\mathrm{II}}(1,2)$ centers bridged by a non centrosymmetric $4,4^{\text {' }}$-bipy bridge, whose pyridine rings form mutual twist angles $\phi_{1,2}^{\prime}$ in the interval $12.3-16.7^{\circ}$.
Figure 7 displays a fragment of a layer with the lost and remaining symmetry centers mapped. Furthermore, the angular distortion of the $\mathrm{Hg}$ coordination sphere, $\left(\Sigma^{\mathrm{tet}}\right)_{1} \approx 81^{\circ}$ and $\left(\Sigma^{\text {tet }}\right)_{2} \approx 86.1^{\circ}$ for $\mathrm{Hg} 1$ and $\mathrm{Hg} 2$ respectively, is a remarkable difference with respect to the $90 \mathrm{~K}$ structure. Nevertheless, these values compensate each other to give an average similar to the one found at $90 \mathrm{~K}$.

It is worth mentioning that there are relatively short interlayer $\mathrm{Hg} \cdots \mathrm{Hg}$ distances. However, they are found in the interval 4.069(5) $\AA(220 \mathrm{~K})-3.836(4) \AA(15 \mathrm{~K})$ suggesting the occurrence of very weak intermetallic $\mathrm{Hg} \cdots \mathrm{Hg}$ metallophilic interactions. ${ }^{81}$

Phase 6, low symmetry, HS* structure $\gamma_{\mathrm{HS}} \approx 1$. After irradiation at $15 \mathrm{~K}$ the LS single crystal becomes HS, as observed with the color change. However, the photogenerated HS state, HS*, retains the same low-symmetry structure described for the LS state at $80 \mathrm{~K}$ and $15 \mathrm{~K}$ with a doubled unit cell characterized by the appearance of Bragg peaks at $\boldsymbol{Q}_{\boldsymbol{c} 2}=1 / 2 \boldsymbol{b}^{*}+1 / 2 \boldsymbol{c}^{*}$ with respect to the HS phase reached at thermal equilibrium. The unit cell contains one noncentrosymmetric $\mathrm{Fe}^{\mathrm{II}}$ site with average $\mathrm{Fe}-\mathrm{N}$ bond length slightly smaller, $\langle\mathrm{Fe} 1-\mathrm{N}\rangle=2.141(3) \AA$, than that of the HS state at $220 \mathrm{~K}$ (probably due to incomplete conversion of the crystal) but similar $\Sigma^{\text {oct }}=11.3^{\circ}$ value. There are also two distinct $\mathrm{Hg}^{\mathrm{II}}$ centers linked by noncentrosymmetric 4,4'-bipy bridges which differ in $\mathrm{Hg}-\mathrm{S}$ bond lengths and $\mathrm{Hg}(1,2)\left(\Sigma^{\text {tet }}\right)_{\mathrm{i}}$ values. A superposition of the HS $(220 \mathrm{~K})$ and HS* $(15 \mathrm{~K})$ exactly maps the same distribution of retained and lost inversion centers shown in Figure 7 for the LS states.

\section{CONCLUSIONS}

Compound 1 represents the first member of a new family of 2D SCO coordination polymers constituted of in situ generated $\left\{\left[\mathrm{Hg}^{\mathrm{II}}(\mathrm{SCN})_{3}\right]_{2}(\mu-4,4\right.$ '-bipy $\left.)\right\}$ building blocks. Furthermore, as far as we know, this compound represents the first example in which four $\mathrm{NCS}^{-}$groups occupy the equatorial positions of a $\mathrm{SCO}\left[\mathrm{Fe}^{\mathrm{II}} \mathrm{N}_{6}\right]$ chromophore, while the axial positions are occupied by a pyridine-like ligand. Usually, the opposite situation is the commonly observed in SCO complexes. ${ }^{82-85,78}$ Indeed, one should not expect SCO behavior for a $\left\{\mathrm{Fe}^{\mathrm{II}}(\mathrm{NCS})_{4}(\text { pyridine-like) }\}_{\mathrm{n}}\right.$ moiety because the ligand field strength of the $\mathrm{NCS}^{-}$is smaller than that of common pyridine- like ligands, and hence the HS state should be the ground state at all temperatures. This is particularly true for 4,4'bipy, for example, the 1D compound $\left[\mathrm{Fe}^{\mathrm{II}}(4,4\right.$ 'bipy $\left.)(\mathrm{bt})(\mathrm{NCS})_{2}\right]$ combining a bridging 4,4 'bipy with the medium-strong $\alpha$-diimine bidentate ligand 2,2'bithiazoline (bt) and two cis-NCS ${ }^{-}$anions remains essentially HS at all temperatures. ${ }^{86}$ Similarly, in the $2 \mathrm{D}$ coordination polymer $\left[\mathrm{Fe}\left(4,4^{\prime} \text { 'bipy }\right)_{2}(\mathrm{NCS})_{2}\right] \cdot$ nSolvent the $\mathrm{Fe}^{\mathrm{II}}$ is equatorially surrounded by four bridging 4,4 'bipy ligands and two terminal trans- $\mathrm{NCS}^{-}$groups but remains $\mathrm{HS}$ for a representative series of solvents and even the unsolvated derivate. ${ }^{87}$ The HS persists when increasing the ligand field strength replacing $\mathrm{NCS}^{-}$with the $\left[\mathrm{Ag}(\mathrm{CN})_{2}\right]^{-}$anion to form the Hofmann-like 3D coordination polymer $\left\{\mathrm{Fe}^{\mathrm{II}}(4,4 \text { 'bipy })_{2}\left[\mathrm{Ag}(\mathrm{CN})_{2}\right]_{2}\right\}{ }^{88}$ The only exception in this series corresponds to the $\left[\mathrm{Fe}(4,4 \text { 'bipy })_{2}(\mathrm{NCX})_{2}\right] \cdot$ nSolvent system when $n$ Solvent $=4 \mathrm{CHCl}_{3}$. For $\mathrm{X}=\mathrm{S}$ the compound displays a cooperative two-step transition in the interval of temperatures $80-160 \mathrm{~K}$ while for $\mathrm{X}=\mathrm{Se}$ only a half cooperative SCO occurs centered at ca. $160 \mathrm{~K}$. The presence of 4 densely packed $\mathrm{CHCl}_{3}$ molecules around the $\mathrm{Fe}^{\mathrm{II}}$ sites provides enough chemical pressure to observe SCO in both derivatives. ${ }^{51}$ Similarly, we invoke the occurrence of an 
effective ligand field strength stemming from the rigid and densely packed layers to explain the observation of SCO in $\mathbf{1}$. On one hand, the resulting strong elastic interaction may induce mechanical frustration responsible for the formation of long-range order HS and LS states of different molecular volume. On the other hand, the thermal contraction increases the molecular packing and drives ligand ordering.

The title compound shows an unusual response to thermal and light stimuli, associated with 6 different phases with different HS fraction and different symmetry breaking due to spin state ordering and/or ligand ordering. When the complex moves from the HS phase 1 ( $\gamma_{\mathrm{HS}}=1$, high symmetry) state to the commensurate SSCW phase $2\left(\gamma_{\mathrm{HS}} \approx 1 / 2\right)$ the unit cell doubles to host two crystallographically distinct $\mathrm{Fe}^{\mathrm{II}}$ centers, one HS and other LS. In this commensurate state the HS and LS centers are segregated in the crystal forming a SSCW corresponding to a periodic alternation of HS and LS stripes. By contrast, at slightly lower temperatures the subsequent step towards the incommensurate phase $3\left(\gamma_{\mathrm{HS}} \approx 1 / 3\right)$ involves another SSCW with a periodicity incommensurate with the molecular lattice. This incommensurate state is erased at 90 $\mathrm{K}$ when the system attains the LS1 phase $4,\left(\gamma_{\mathrm{HS}} \approx 0\right)$ characterised by a unit cell equivalent to that described at 220 $\mathrm{K}$ but with smaller dimensions due to thermal compression and spin conversion. However, upon further cooling, doubling of this unit cell occurs and a low symmetric LS2 phase 5 appears. Interestingly, the metastable photogenerated metastable HS* phase 6 retains this low symmetry, thus generating a phase distinct from the HS state observed at thermal equilibrium. This underlines the possibility to generate by light false ground states, which are never reached at thermal equilibrium. Examples of photo-induced polymorphism have been described for $\left\{\mathrm{Fe}^{\mathrm{II}}\left[\mathrm{H}_{2} \mathrm{~B}(\mathrm{pz})_{2}\right]_{2} \text { phen }\right\}^{89}$ and $\left[\mathrm{Fe}^{\mathrm{II}} \mathrm{H}_{2} \mathrm{~L}_{2} \mathrm{Me}\right]\left(\mathrm{PF}_{6}\right)_{2}{ }^{34}$ $\left(\left[\mathrm{H}_{2} \mathrm{~B}(\mathrm{pz})_{2}\right]^{-}=\right.$hydrobis-pyrazolylborate; phen $=1,10-$ phenanthroline; $\mathrm{H}_{2} \mathrm{~L}_{2} \mathrm{Me}=$ bis [N-(2-methylimidazol-4-yl) methylidene-3 aminopropyl] ethylenediamine).

A common denominator in the whole sequence of phase transitions observed for $\mathbf{1}$ is the change of twist angle $\phi$ of the crystallographically different 4,4 'bipy ligands (Figure 5 ) on the $\mathrm{Fe}$ sites. When 1 changes from the HS state to the commensurate HS:LS (phase 2) and subsequently to the incommensurate $\approx 2$ LS:HS (phase 3), the 4,4'bipy losses the inversion symmetry. By contrast, the $\mathrm{Hg}-4,4$ '-bipy- $\mathrm{Hg}$ moiety remains centrosymmetric in the HS (phase 1), HS:LS (phase 2) and LS1 (phase 4) states but $\phi^{\prime}$ dramatically increases in the $\approx 2$ LS:HS (phase 3), LS2 (phase 5) and HS* (phase 6) states. These changes in $\phi$ and $\phi^{\prime}$ reflect the way in which the layers accommodate the structural modification of the $\left[\mathrm{FeN}_{6}\right]$ centers.

It is well known that entropy plays an important role in such transformations. The HS state is favored at high temperature with respect to the LS state of lower entropy and SCO occurs at thermal equilibrium from LS to HS states as temperature rises. This is described by the thermal evolution of the HS fraction $\gamma_{\mathrm{HS}}$, which is a totally symmetric order parameter. But this is also true for structural aspects: high symmetry states are also favored at high temperature with respect to low symmetry states of lower entropy. The appearance of different orders can be described in the Landau theory of phase transition by non-zero symmetry breaking order parameters. The first order parameter, $\eta$, describes both HS/LS and ligand order in phase $2(\eta \neq 0$ between 108 and $125 \mathrm{~K})$. The structural order in phase 3, related to ligand and spin-state order, is described by another order parameter, $\lambda(\lambda$ $\neq 0$ only in phase 3 , between 96 and $108 \mathrm{~K}$ ). The ligand order in phase 5 is due to another type of cell doubling and a third symmetry breaking order parameter, $\mu(\mu \neq 0$ in phase 5 and 6 ). Therefore the phase diagram is very complicated to describe since $\gamma_{\mathrm{HS}}$ is strongly coupled to the three different symmetry breaking order parameters. The different phases associated with different order parameters compete.
Phase 1: $\gamma_{\mathrm{HS}}=1$,
Phase 2: $\gamma_{\mathrm{HS}} \approx 0.5$, $\eta=0, \lambda=0$ and $\mu=0$
Phase 3: $\gamma_{\mathrm{HS}} \approx 0.34$,
Phase 4: $\gamma_{\mathrm{HS}}=0$, $\eta \neq 0, \lambda=0$ and $\mu=0$
Phase 5: $\gamma_{\mathrm{HS}}=0$, $\eta=0, \lambda \neq 0$ and $\mu=0$ $\eta=0, \lambda=0$ and $\mu=0$
Phase 6: $\gamma_{\mathrm{HS}}=1$, $\eta=0, \lambda=0$ and $\mu \neq 0$ $\eta=0, \lambda=0$ and $\mu \neq 0$

The appearance of different phases and the corresponding phase transitions can be described through the complex development of the non-equilibrium free energy

$\mathrm{F}=\mathrm{a}_{1} \gamma_{\mathrm{HS}}+\mathrm{a}_{2} \gamma_{\mathrm{HS}}{ }^{2}+\mathrm{b}_{1} \eta^{2}+\mathrm{c}_{1} \gamma_{\mathrm{HS}} \eta^{2}+\mathrm{c}_{2} \gamma_{\mathrm{HS}} \lambda^{2}+\mathrm{c}_{3} \gamma_{\mathrm{HS}} \mu^{2}+\mathrm{d}_{1} \mu^{2} h^{2}$ $+\mathrm{d}_{2} \mu^{2} \lambda^{2}+\mathrm{d}_{2} \eta^{2} \lambda^{2}+\ldots$

as done for the more simple case where a single intermediate HS-LS phase appear. ${ }^{90}$ The phase diagram becomes then multi-dimensional and difficult to describe. However, we can describe experimentally the different types of phase transitions. A phase transition from low-symmetry LS state (phase 5) to high symmetry LS state (phase 4) occurs as temperature rises, but in a temperature range $(<95 \mathrm{~K})$ where the LS state is stable. At higher temperature the HS state is favored and the crossover occurs, in steps because of elastic frustration. But the phase transition from a low symmetry HS to a high symmetry HS state is not observed at thermal equilibrium because the low symmetry HS state is not stable at high temperature. It is only observed after LIESST below $50 \mathrm{~K}$, where the ligands order in the metastable HS state. It is therefore the competition between the different types of orders, involving both spin-state order and ligand order, which is responsible for the multistability and the formation of the 6 different phases observed here.

\section{METHODS \\ Experimental Section \\ General}

Variable-temperature magnetic susceptibility data were recorded for single crystals and microcrystalline samples of 1 at scanning rates $0.3,0.5$ and $1 \mathrm{~K} / \mathrm{min}$ with a Quantum Design MPMS2 SQUID susceptometer equipped with a $7 \mathrm{~T}$ magnet, operating at $1 \mathrm{~T}$ and at temperatures $2-400 \mathrm{~K}$. Experimental susceptibilities were corrected from diamagnetism of the constituent atoms by the use of Pascal's constants. Infrared spectra were recorded on a Nicolet 5700 spectrometer in the range 4000-400 $\mathrm{cm}^{-1}$. Elemental analysis $(\mathrm{C}, \mathrm{H}, \mathrm{N})$ were performed using a LECO CHNS-932 analyzer.

Single-crystal X-ray data at $220 \mathrm{~K}, 117 \mathrm{~K}, 102 \mathrm{~K}, 90 \mathrm{~K}$, $80 \mathrm{~K}, 15 \mathrm{~K}$ and $15 \mathrm{~K}$ under irradiation for 1 were collected on an Oxford Diffraction Xcalibur3 using MoK $\alpha$ radiation $(\lambda=$ $0.71073 \AA$ ) for three different crystals. The changes of the unit cell volume and cell parameters have been investigated during sample heating and cooling modes on the same crystal at the scanning rate of $\sim 0.1 \mathrm{~K} / \mathrm{min}$ (Figure S1 and S3). We used an Oxford Cryosystems nitrogen-flow cryostat for measurements at low temperature down to $80 \mathrm{~K}$ and Helijet helium-flow cryostat for measurements at $15 \mathrm{~K}$. The difference in thermal behavior between X-ray and magnetism data is due to kinetics effects. No sample fatigue or memory has been identified. In addition, no HS state trapping of $\mathbf{1}$ has been observed down to $80 \mathrm{~K}$. A data scaling and empirical or 
multi-scan absorption correction was performed with CrysAlisPro software by Rigaku Oxford Diffraction. The structures were solved by direct methods using SHELXT and refined by full-matrix least squares on $\mathrm{F}^{2}$ using SHELXL$97^{91,92}$ with the exception of the phase 3 at $102 \mathrm{~K}$. All nonhydrogen atoms were refined anisotropically. H-atoms were constrained by geometry. When applicable, SIMU and ISOR restrains as well EADP constrain were applied for occupational disorder. For the aperiodic structure at $102 \mathrm{~K}^{70}$ further least square refinement on $\mathrm{F}$ were performed with JANA2006. ${ }^{93-95}$ This refinement considers modulation of the atomic positions for all non-H atoms. The modulation of the selected geometry parameters along the superspace coordinate $\mathrm{x}_{4}$ for incommensurate were calculated in $3 \mathrm{D}$ space of $\mathrm{P} 1$ cell based on a set of refined modulation parameters for system 1. The results were visualized and extracted by the use of Grapht tool of Jana2006.

The overview of crystal data and refinement parameters for all phases is given in tables S2. For additional details, please, see CCDC 1457779 (15 K dark); 1457780 (15 K irradiated); $1457781(90 \mathrm{~K})^{70} ; 1457782(117 \mathrm{~K})^{70} ; 1457783$ $(220 \mathrm{~K})^{70} ; 1457784(80 \mathrm{~K})$; and $1457785(102 \mathrm{~K})^{70}$. This supplementary data can be obtained free of charge via www.ccdc.cam.ac.uk/conts/retrieving.html (or from the Cambridge Crystallographic Data Centre, 12 Union Road, Cambridge CB2 1EZ, UK; fax: (+44) 1223-336-033; or deposit@ccdc.ca.ac.uk).

\section{Materials}

\section{Metal complex synthesis.}

Compound 1 was obtained by diffusion in three-arms $\mathrm{H}$ type vessels. One side of the vessel contained an aqueous solution $(2 \mathrm{~mL})$ of $\mathrm{FeCl}_{2}(0.10 \mathrm{mmol}, 12.7 \mathrm{mg})$ while the middle arm contained a water solution of $\mathrm{K}_{2}\left[\mathrm{Hg}(\mathrm{SCN})_{4}\right](2$ $\mathrm{mL})$ prepared in situ by mixing $\mathrm{Hg}(\mathrm{SCN})_{2}(0.1 \mathrm{mmol})$ and KSCN $(0.2 \mathrm{mmol})$. The other side of the vessel contained a methanol solution ( $2 \mathrm{~mL}$ ) of 4,4'-bipy $(0.10 \mathrm{mmol}, 15.6 \mathrm{mg})$. The three-arms were filled with methanol, sealed and left in a quiet place. Light-orange block-like crystals of 1 suitable for single crystal X-ray analysis were obtained after about one week. Mw 1117.87; Yield ca. $45 \mathrm{mg}$ (ca. 40\%); IR ( $\mathrm{cm}^{-1}$, room temperature). The most striking feature of the IR spectrum is a intense multiple band with peaks at 2147, 2138, and $2121 \mathrm{~cm}^{-1}$ and two less intense shoulder at 2095 and 2070 $\mathrm{cm}^{-1}$ which corresponds to the $v(\mathrm{CN})$ stretching modes of the distinct $\mathrm{NCS}^{-}$groups (see Fig. S6, Supporting Information). Anal. Found $\mathrm{C}$ 27.46, $\mathrm{H}$ 1.41, N 12.28; Calcd for $\mathrm{C}_{26} \mathrm{H}_{16} \mathrm{FeHg}_{2} \mathrm{~N}_{10} \mathrm{~S}_{6}, \mathrm{C} 27.94, \mathrm{H}$ 1.44, N 12.53.

\section{ASSOCIATED CONTENT \\ Supporting Information}

The Supporting Information is available free of charge on the ACS Publications website at DOI:---.

Figure S1: overlay of the thermal dependences of $\chi_{M} T$ and Volume of the unit cell; Figure S2: pictures showing the thermochromic properties of 1; Figure S3: thermal dependence of lattice parameters $a, b$ and $c$; Figures S4,S5: ORTEP representation of a fragment of a layer of $\mathbf{1}$ at $90 \mathrm{~K}$ and 80-15 K, respectively; Figure S6: Infra-red spectrum of 1; Tables S1-S3 contain rate constants of the HS* $\rightarrow$ LS relaxation, crystallographic data and selected bond angles for 1.

\section{Corresponding Author}

E-mail: eric.collet@univ-rennes1.fr; jose.a.real@uv.es

\section{Notes}

The authors declare no competing financial interest.

\section{ACKNOWLEDGEMENTS}

This work was supported by the Spanish Ministerio de Economia y Competitividad (MINECO), FEDER (CTQ2013-46275-P and CTQ2016-78341-P), Unidad de Excelencia María de Maeztu (MDM-2015-0538), the Generalitat Valenciana through PROMETEO/2016/147, and the Institut Universitaire de France, the National Research Agency (ANR-13-BS04-0002), Rennes Metropole and CNRS (Post-Doc funding of E.T.). L.P.L. and F.J.V.M. thank to the Universidad de Valencia and a MINECO for a predoctoral (FPI) grant. Prof. D. Zhang thanks for the support from the Natural Science Foundation of China (21671121). 


\section{REFERENCES}

(1) Goodwin, H. A. Coord. Chem. Rev. 1976, 18, 293-

325 .

(2) Gütlich, P. Struct. Bonding (Berlin) 1981, 44, 83-

195.

(3) König, E.; Ritter, G.; Kulshreshtha, S. K. Chem. Rev. 1985, 85, 219-234.

(4) Hauser, A. Comments Inorg. Chem. 1995, 17, 17-40.

(5) König, E. Struct. Bonding (Berlin) 1991, 76, 51-152.

(6) Gütlich, P.; Hauser, A.; Spiering, H. Angew. Chem., Int. Ed. Engl. 1994, 33, 2024-2054.

(7) Sato, O. Acc. Chem. Res. 2003, 36, 692-700.

(8) Real, J. A.; Gaspar, A. B.; Niel, V.; Muñoz, M. C. Coord. Chem. Rev. 2003, 236, 121-141.

(9) Gütlich, P.; Goodwin, H. A. Eds., Top. Curr. Chem. 2004, Vols. 233-235.

(10) Real, J. A.; Gaspar, A. B.; Muñoz, M. C. Dalton Trans. 2005, 2062-2079.

(11) Halcrow, M. A. Polyhedron 2007, 26, 3523-3576

(12) Halcrow, M. A. Coord. Chem. Rev. 2009, 253, 2493-

2514.

(13) Olguin, J.; Brooker, S. Coord. Chem. Rev. 2011, 255, 203-240.

(14) Bousseksou, A.; Molnár, G.; Salmon, L.; Nicolazzi, W. Chem. Soc. Rev. 2011, 40, 3313-3335.

(15) Meded, V.; Bagrets, A.; Fink, K.; Chandrasekar, R.; Ruben, M.; Evers, F.; Bernand-Mantel, A.; Seldenthuis, J. S.; Beukman, A.; van der Zant, H. S. J. Phys. Rev. B 2011, 83, 245415(1-13).

(16) Prins, F.; Monrabal-Capilla, M.; Osorio, E. A.; Coronado, E.; van der Zant, H. S. J. Adv. Mater. 2011, 23, 1545-1549.

(17) Cavallini, M.; Bergenti, I.; Milita, S.; Kengne, J. C.; Gentili, D.; Ruani, G.; Salitros, I.; Meded, V.; Ruben, M. Langmuir 2011, 27, 4076-4081.

(18) Miyamachi, T.; Gruber, M.; Davesne, V.; Bowen, M.; Boukari, S.; Joly, L.; Scheurer, F.; Rogez, G.; Yamada, T. K.; Ohresser, P.; Beaurepaire, E.; Wulfhekel, W. Nat. Commun. 2012, 3, 938 (1-6).

(19) Martinho, P. N.; Rajnak, C.; Ruben, M. in SpinCrossover Materials: Properties and Applications, Halcrow, M. A. Ed. 2013, 376-404, Wiley and references therein.

(20) Shepherd, H. J.; Molnár, G.; Nicolazzi, W.; Salmon, L.; Bousseksou, A. Eur. J. Inorg. Chem. 2013, 653661.

(21) Rotaru, A.; Dugay, J.; Tan, R. P.; Gural'skiy, I. A.; Salmon, L.; Demont, P.; Carrey, J.; Molnár, G.; Respaud, M.; Bousseksou, A. Adv. Mater. 2013, 25, 1745-1749.

(22) Gural'skiy, I. A.; Quintero, C. M.; Sánchez Costa, J.; Demont, P.; Molnár, G.; Salmon, L.; Shepherd, H. J.; Bousseksou, A. J. Mater. Chem. C 2014, 2, 29492955.

(23) Bartual-Murgui, C.; Akou, A.; Thibault, C.; Molnár, G.; Vieu, C.; Salmon, L.; Bousseksou, A. J. Mater. Chem. C 2015, 3, 1277-1285.

(24) Aragonés, A. C.; Aravena, D.; Cerdá, J. I.; AcísCastillo, Z.; Li, H.; Real, J. A.; F. Sanz, F.; Hihath, J.; Ruiz, E.; Díez-Pérez, I. Nano Lett. 2016, 16, 218226.
(25) Boinnard, D.; Bousseksou, A.; Dworkin, A.; Savariault, J. M.; F. Varret, F.; Tuchagues, J. P. Inorg. Chem. 1994, 33, 271-281.

(26) Reger, D. L.; Little, C. A.; Young Jr., V. G.; Pink, M. Inorg. Chem. 2001, 40, 2870-2874.

(27) Chernyshov, D.; Hostettler, M.; Törnroos, K. W.; Bürgi, H. B. Angew. Chem. Int. Ed. 2003, 42, 38253830.

(28) Huby, N.; Guérin, L.; Collet, E.; Toupet, L.; Ameline, J. C.; Cailleau, H.; Roisnel, T.; Tayagaki, T.; Tanaka, K. Phys. Rev. B 2004, 69, 020101(R).

(29) Guérin, L.; Huby, N.; Collet, E.; Toupet, L.; Cailleau, H.; Tanaka, K. J. Phys: Conf. Series 2005, 21, 136-141.

(30) Money, V. A.; Carbonera, C.; Elhaïk, J.; Halcrow, M. A.; Howard, J. A. K.; Létard, J. F. Chem. Eur. J. 2007, 13, 5503-5514.

(31) Luan, J.; Zhou, J.; Liu, Z.; Zhu, B.; Wang, H.; Bao, X.; Liu, W.; Tong, M. L.; Peng, G.; Peng, H.; Salmon, L.; Bousseksou, A. Inorg. Chem. 2015, 54, 5145-5147.

(32) Yamada, M.; Hagiwara, H.; Torigoe, H.; Matsumoto, N.; Kojima, M.; Dahan, F.; Tuchagues, J. P.; Re, N.; Iijima, S. Chem. Eur. J. 2006, 12, 45364549.

(33) Sato, T.; Nishi, K.; Iijima, S.; Kojima, M.; Matsumoto, N. Inorg. Chem. 2009, 48, 7211-7229.

(34) Bréfuel, N.; Collet, E.; Watanabe, H.; Kojima, M.; Matsumoto, N.; Toupet, L.; Tanaka, K.; Tuchagues, J. P. Chem. Eur. J. 2010, 16, 14060-14068.

(35) Bréfuel, N.; Watanabe, H.; Toupet, L.; Come, J.; Matsumoto, N.; Collet, E.; Tanaka, K.; Tuchagues, J. P. Angew. Chem. Int. Ed. 2009, 48, 9304-9307.

(36) Bonnet, S.; Siegler, M. A.; Sánchez-Costa, J.; Molnár, G.; Bousseksou, A.; Spek, A. L.; Gamez, P.; Reedijk, J. Chem. Commun. 2008, 5619-5621.

(37) Létard, J. F.; Guionneau, P.; Codjovi, E.; Lavastre, O.; Bravic, G.; Chasseau, D.; Kahn, O. J. Am. Chem. Soc. 1997, 119, 10861-10862.

(38) Collet, E.; Watanabe, H.; Bréfuel, N.; Palatinus, L.; Roudaut, L.; Toupet, L.; Tanaka, K.; Tuchagues, J. P.; Fertey, P.; Ravy, S.; Toudic, B.; Cailleau, H. Phys. Rev. Lett. 2012, 109, 257206 (1-5).

(39) Pillet, S.; Bendeif, E. E.; Bonnet, S.; Shepherd, H. J.; Guionneau, P. Phys. Rev. B, 2012, 86, 064106 (111).

(40) Nakano, K.; Kawata, S.; Yoneda, K.; Fuyuhiro, A.; Yagi, T.; Nasu, S.; Morimoto, S.; Kaizaki, S. Chem. Commun. 2004, 2892-2893.

(41) Klingele, M. H.; Moubaraki, B.; Cashion, J. D.; Murray, K. S.; Brooker, S. Chem. Commun. 2005, 987-989.

(42) Fedaoui, D.; Bouhadja, Y.; Kaiba, A.; Guionneau, P.; Létard, J. F.; Rosa, P. Eur. J. Inorg. Chem. 2008, 1022-1026.

(43) Kaiba, A.; Shepherd, H. J.; Fedaoui, D.; Rosa, P.; Goeta, A. E.; Rebbani, N.; Létard, J. F.; Guionneau, P. Dalton Trans. 2010, 39, 2910-2918.

(44) Agustí, G.; Gaspar, A. B.; Muñoz, M. C.; Real, J. A. Inorg. Chem. 2007, 46, 9646-9654.

(45) Quesada, M.; Prins, F.; Bill, E.; Kooijman, H.; Gamez, P.; Roubeau, O.; Spek, A. L.; Haasnoot, J. G.; Reedijk, J. Chem. Eur. J. 2008, 14, 8486-8499. 
(46) Halder, G. J.; Chapman, K. W.; Neville, S. M.; Moubaraki, B.; Murray, K. S.; Létard, J. F.; Kepert, C. J. J. Am. Chem. Soc. 2008, 130, 17552-17562.

(47) Agustí, G.; Muñoz, M. C.; Gaspar, A. B.; Real, J. A. Inorg. Chem. 2008, 47, 2552-2561.

(48) Kosone, T.; Kachi-Terajima, C.; Kanadani, C.; Saito, T.; Kitazawa, T. Chem. Lett. 2008, 37, 422423.

(49) Martínez, V.; Gaspar, A. B.; Muñoz, M. C.; Bukin, G. V.; Levchenko, G.; Real, J. A. Chem. Eur. J. 2009, 15, 10960-10971.

(50) Agustí, G.; Gaspar, A. B.; Muñoz, M. C.; Lacroix, P. G.; Real, J. A. Aust. J. Chem. 2009, 62, 1155-1165.

(51) Adams, C. J.; Muñoz, M. C.; Waddington, R. E.; Real, J. A. Inorg. Chem. 2011, 50, 10633-10642.

(52) Bauer, W.; Pfaffeneder, T.; Achterhold, K.; Weber, B. Eur. J. Inorg. Chem. 2011, 3183-3192.

(53) Lin, J.-B.; Xue, W.; Wang, B.-Y.; Tao, J.; Zhang, W.-X.; Zhang, J.-P.; Chen, X.-M. Inorg. Chem. 2012, 51, 9423-9430.

(54) Shatruk, M.; Phana, H.; Chrisostomoa, B. A.; Suleimenov, A. Coord. Chem. Rev. 2015, 289-290, 62-73.

(55) Ortega-Villar, N.; Muñoz, M. C.; Real, J. A. Magnetochemistry, 2016, 2, 16 (1-22).

(56) Griffin, M.; Shakespeare, S.; Shepherd, H. J.; Harding, C. J.; Létard, J. F.; Desplanches, C.; Goeta, A. E.; Howard, J. A. K.; Powell, A. K.; Mereacre, V.; Garcia, Y.; Naik, A. D.; Müller-Bunz, H.; Morgan, G. G. Angew. Chem. Int. Ed. 2011, 50, 896900.

(57) Li, Z. Y.; Dai, J. W.; Shiota, Y.; Yoshizawa, K.; Kanegawa, S.; Sato, O. Chem. Eur. J. 2013, 19, 12948-12952.

(58) Vieira, B. J. C.; Coutinho, J. T.; Santos, I. C.; Pereira, L. C. J.; Waerenborgh, J. C.; da Gama, V. Inorg. Chem. 2013, 52, 3845-3850.

(59) Murnaghan, K. D.; Carbonera, C.; Toupet, L.; Griffin, M.; Dîrtu, M. M.; Desplanches, C.; Garcia, Y.; Collet, E.; Létard, J. F.; Morgan, G. G. Chem. Eur. J. 2014, 20, 5613-5618.

(60) Harding, D. J.; Phonsri, W.; Harding, P.; Murray, K. S.; Moubaraki, B.; Jameson, G. N. L. Dalton Trans. 2015, 44, 15079-15082.

(61) Bhar, K.; Khan, S.; Sánchez-Costa, J.; Ribas, J.; Roubeau, O.; Mitra, P.; Ghosh, B. K.; Angew. Chem. Int. Ed. 2012, 51, 2142-2145.

(62) Fitzpatrick, A. J.; Trzop, E.; Müller-Bunz, H.; Dîrtu, M. M.; Garcia, Y.; Collet, E.; Morgan, G. G. Chem. Commun. 2015, 51, 17540-17543.

(63) Watanabe, H.; Tanaka, K.; Bréfuel, N.; Cailleau, H.; Létard, J. F.; Ravy, S.; Fertey, P.; Nishino, M.; Miyashita, S.; Collet, E. Phys. Rev. B 2016, 93, 014419 (1-12).

(64) Paez-Espejo, M.; Sy, M.; Boukheddaden, K. J. Am. Chem. Soc. 2016, 138, 3202-3210.

(65) Marino, A.; Buron-Le Cointe, M.; Lorenc, M.; Toupet, L.; Henning, R.; DiChiara, A. D.; Moffat, K.; Bréfuel, N.; Collet, E. Faraday Discuss. 2015, 177, 363-379.

(66) Nihei, M.; Tahira, H.; Takahashi, N.; Otake, Y.; Yamamura, Y.; Saito, K.; Oshio, H. J. Am. Chem. Soc. 2010, 132, 3553-3560.

(67) Sciortino, N. F.; Scherl-Gruenwald, K. R.; Chastanet, G.; Halder, G. J.; Chapman, K. W.;
Létard, J. F.; Kepert, C. J. Angew. Chem. Int. Ed. 2012, 51, 10154-10158.

(68) Clements, J. E.; Price, J. R.; Neville, S. M.; Kepert, C. J. Angew. Chem. Int. Ed. 2016, 55, 15105-15109.

(69) Sciortino, N. F.; Zenere, K. A.; Corrigan, M. E.; Halder, G. J.; Chastanet, G.; Létard, J. F.; Kepert, C. J.; Neville, S. M. Chem. Sci. 2017, 8, 701-707.

(70) Trzop, E.; Zhang, D.; Piñeiro-Lopez, L.; ValverdeMuñoz, F. J.; Muñoz, M. C.; Palatinus, L.; Guerin, L.; Cailleau, H.; Real, J. A.; Collet, E. Angew. Chem. Int. Ed. 2016, 55, 8675-8679.

(71) Decurtins, S.; Gütlich, P.; Köhler, C. P.; Spiering, H.; Hauser, A. Chem. Phys. Lett. 1984, 105, 1-4.

(72) Létard, J. F. J. Mater. Chem. 2006, 16, 2550-2559.

(73) Martínez, V.; Arcís-Castillo, Z.; Muñoz, M. C.; Gaspar, A. B.; Etrillard, C.; Létard, J. F.; Terekhov, S. A.; Bukin, G. V.; Levchenko, G.; Real, J. A. Eur. J. Inorg. Chem. 2013, 813-818.

(74) Guionneau, P.; Marchivie, M.; Bravic, G.; Létard, J. F.; Chasseau, D. J. Mater. Chem. 2002, 12, 2546-2551.

(75) Adams, C. J.; Muñoz, M. C.; Waddington, R. E.; Real, J. A. Inorg. Chem. 2011, 50, 10633-10642.

(76) Li, J.-Y.; Yan, Z.; Ni, Z.-P.; Zhang, Z.-M.; Chen, Y.C.; Liu, W.; Tong, M.-L. Inorg. Chem. 2014, 53, 4039-4045. (77) Neville, S. M.; Halder, G. J.; Chapman, K. W., Duriska, M. B.; Southon, P. D.; Cashion, J. D.; Létard, J. F.; Moubaraki, B.; Murray, K. S., Kepert, C. J. J. Am. Chem. Soc. 2008, 130, 2869-2876.

(78) Romero-Morcillo, T.; De la Pinta, N.; Callejo, L. M.; Piñeiro-López, L.; Muñoz, M. C.; Madariaga, G.; Ferrer, S.; Breczewski, T.; Cortés, R.; Real, J. A. Chem. Eur. J. 2015, 21, 12112-12120.

(79) Morsali, A.; Masoomi, M. Y. Coord. Chem. Rev. 2009, 253, 1882-1905.

(80) Real, J. A.; Gallois, B.; Granier, T.; Suez-Panamá; Zarembowitch, J. Inorg. Chem. 1992, 31, 49724979.

(81) Pyykko, P.; Straka, M. Phys. Chem. Chem. Phys. 2000, 2, 2489-2493.

(82) Real, J. A.; Andrés, E.; Muñoz, M. C.; Julve, M.; Granier, T.; Bousseksou, A.; Varret, F. Science 1995, 268, 265-267.

(83) Halder, G. J.; Kepert, C. J.; Moubaraki, B.; Murray, K. S.; Cashion, J. D. Science 2002, 298, 1762-1765.

(84) Neville, S. M.; Moubaraki, B.; Murray, K. S.; Kepert, C. J. Angew. Chem. Int. Ed. 2007, 46, 20592062.

(85) Neville, S. M.; Halder, G. J.; Chapman, K. W.; Duriska, M. B.; Moubaraki, B.; Murray, K. S.; Kepert, C. J. J. Am. Chem. Soc. 2009, 131, 1210612108.

(86) Moliner, N.; Muñoz, M. C.; Létard, S.; Salmon, L.; Tuchagues, J. P.; Bousseksou, A.; Real, J. A. Inorg. Chem. 2002, 41, 6997-7005.

(87) Adams, C. J.; J. A. Real, J. A.; Waddington, R. E. CrystEngComm. 2010, 12, 3547-3553.

(88) Niel, V.; Muñoz, M. C.; Gaspar, A. B.; Galet, A.; Levchenko, G.; Real, J. A. Chem. Eur. J. 2002, 11, 2446-2453.

(89) Thompson, A. L.; Goeta, A. E.; Real, J. A.; Galet, A.; Muñoz, M. C. Chem. Commun. 2004, 13901391.

(90) Chernyshov, D.; Bürgi, H.-B. Hostettler, M. Phys. Rev. B 2004, 70, 094116(1-7). 
(91) Sheldrick, G. M. Acta Crystallogr., Sect. A: Fundam. Crystallogr. 2015, 71, 3-8.

(92) Sheldrick, G. M. Acta Crystallogr., Sect. A: Fundam. Crystallogr. 2008, 64, 112-122.

(93) Petricek, V.; Dusek, M.; Palatinus, L. JANA2006, Institute of Physics, Praha, Czech Republic, 2006.

(94) Petricek, V.; Dusek, M.; Palatinus, L. Z. Kristallogr. 2014, 229(5), 345-352.
(95) Palatinus, L.; Chapuis, G. J. Appl. Cryst. 2007, 40, 786-790.

Table 1. Selected bond lengths for compound $\mathbf{1 .}$

\begin{tabular}{|c|c|c|c|c|c|c|c|}
\hline & Phase 1 & Phase 2 & Phase $3^{\#}$ & Phase 4 & \multicolumn{2}{|c|}{ Phase 5} & Phase 6 \\
\hline & $220 \mathrm{~K}$ & $117 \mathrm{~K}$ & $102 \mathrm{~K}$ & $90 \mathrm{~K}$ & $80 \mathrm{~K}$ & $15 \mathrm{~K}$ & $15 * \mathrm{~K}$ \\
\hline Hg1-S1A & $2.51(2)$ & $2.5878(11)$ & $2.570(2)$ & $2.5733(8)$ & $2.5062(13)$ & $2.506(2)$ & $2.5238(14)$ \\
\hline Hg1-S1B & $2.61(3)$ & & & & & & \\
\hline Hg1-S2 & $2.5152(10)$ & $2.5028(11)$ & $2.510(3)$ & $2.5065(9)$ & $2.5703(11)$ & $2.575(2)$ & $2.5463(11)$ \\
\hline $\mathrm{Hg} 1-\mathrm{S} 3$ & $2.4253(11)$ & $2.4368(12)$ & $2.434(7)$ & $2.4345(10)$ & $2.4400(14)$ & $2.442(2)$ & $2.4426(13)$ \\
\hline Hg1-N5 & $2.407(3)$ & $2.391(4)$ & $2.395(7)$ & $2.382(3)$ & $2.384(4)$ & $2.391(6)$ & $2.399(4)$ \\
\hline Hg2-S4 & & $2.5460(11)$ & & & $2.5071(13)$ & $2.509(2)$ & $2.5237(14)$ \\
\hline $\mathrm{Hg} 2-\mathrm{S} 5$ & & $2.5251(11)$ & & & $2.5778(12)$ & $2.582(2)$ & $2.5546(11)$ \\
\hline Hg2-S6 & & $2.4341(13)$ & & & $2.434(2)$ & $2.439(2)$ & $2.4383(13)$ \\
\hline Hg2-N10 & & $2.397(4)$ & & & $2.378(2)$ & $2.383(6)$ & $2.400(4)$ \\
\hline Fe1-N1 & $2.185(3)$ & $2.010(3)$ & $2.067(9)$ & $2.004(3)$ & $2.002(4)$ & $2.010(5)$ & $2.165(4)$ \\
\hline $\mathrm{Fe} 1-\mathrm{N} 2$ & $2.153(3)$ & $1.949(3)$ & $2.010(9)$ & $1.939(3)$ & $1.931(5)$ & $1.939(6)$ & $2.116(4)$ \\
\hline $\mathrm{Fe} 1-\mathrm{N} 3$ & $2.137(3)$ & $1.947(4)$ & $2.003(8)$ & $1.940(3)$ & $1.934(3)$ & $1.943(7)$ & $2.148(5)$ \\
\hline Fe1-N6 & & & & & $1.999(4)$ & $2.009(5)$ & $2.167(4)$ \\
\hline Fe1-N7 & & & & & $1.940(5)$ & $1.933(6)$ & $2.116(4)$ \\
\hline Fe1-N8 & & & & & $1.930(5)$ & $1.927(7)$ & $2.138(5)$ \\
\hline Fe2-N6 & & $2.181(3)$ & & & & & \\
\hline Fe2-N7 & & $2.142(4)$ & & & & & \\
\hline Fe2-N8 & & $2.115(4)$ & & & & & \\
\hline$\Sigma(\mathrm{Fe})$ & 11.24 & $5.52(\mathrm{Fe} 1)$ & & 7.64 & 7.45 & 6.70 & 11.27 \\
\hline & & $15.5(\mathrm{Fe} 2)$ & & & & & \\
\hline$\Sigma(\mathrm{Hg})$ & 79.2 & $87.3(\mathrm{Hg} 1)$ & & 83.7 & $81.5(\mathrm{Hg} 1)$ & $80.4(\mathrm{Hg} 1)$ & $75.7(\mathrm{Hg} 1)$ \\
\hline & & $75.0(\mathrm{Hg} 2)$ & & & $86.0(\mathrm{Hg} 2)$ & $86.2(\mathrm{Hg} 2)$ & $81.1(\mathrm{Hg} 2)$ \\
\hline
\end{tabular}

[*] Under irradiation.

$\left[{ }^{\#}\right]$ Incommensurate Phase: values are averaged over modulation period. 